\title{
Assessing the Relation between Equity Risk Premia and Macroeconomic Volatilities
}

\author{
Renatas Kizys*and Peter Spencer \\ The University of York \\ Department of Economics and Related Studies \\ Heslington, York YO10 5DD
}

April 22, 2006

\begin{abstract}
In this paper, we used modified multivariate EGARCH-M models to assess the relation between the equity risk premium, macroeconomic risk, and inflationary expectations. To rationalise this link between equity risk premia and macroeconomic volatilities, we built our empirical study on the stochastic discount factor (SDF) model. As an innovative feature of our empirical model, we used long-term government bond yields in order to explain this risk-return relation. Our research suggests that stock market investors should use long-term government bond yield for the UK and term spread for the US in order to instrument their assessment of stock market investment opportunities and riskiness. We also document that the relevance of the short-term interest rates has decreased over the last decade, whereas the relevance of the long-term government bond yields, by contrast, has increased. With regard to the risk-return relation, we found the UK investors tend to significantly price in inflation risk premia. Estimation results strongly suggest that the decline in macroeconomic volatilities might have played an increasingly important role in reducing risk premia in the US and, to some extent, in the UK.

Keywords: Asset pricing, Risk premium, Macroeconomic volatility, Stochastic discount factor model, Multivariate EGARCH-M model

JEL classification: C32, E32, E44, G12
\end{abstract}

${ }^{*}$ Corresponding author contact information: e-mail address: rk501@york.ac.uk; phone: +44 1904 433799; fax: +441904433759. 


\section{Introduction}

Should investors price in macroeconomic factors? Because the stock price itself can be characterised as a claim on expected future dividends or cash flows, and the discount rate is thought to be vulnerable to the changing macroeconomic environment investors should clearly ground their investment decisions on economic fundamentals that generate those future cash flows. Although the different asset pricing theories, pioneered by CAPM (Merton, 1973) and APT (Roll and Ross, 1980), and a vast number of empirical studies have studied which macroeconomic determinants and why should be included in the investor's information set for investment-decision making, more than three decades of intensive discussions among financial economists have not provided yet a clear answer to this question.

Finance theory predicts that investors should be rewarded for holding risky assets. If investor's portfolio is exposed to macroeconomic uncertainty, the more uncertain is the payoff on the portfolio of investments he or she holds, the greater reward for holding the portfolio will be required. This macroeconomic uncertainty may vary, for instance, with monetary policy stance of the central bank or with external (e.g., oil price) developments, which lie outside the scope of the central bank. Either way, investors' expectations about future cash flows should be based on economic growth prospects, inflationary environment where a company operates, and interest rates that prevail in money and credit markets.

Exploring the relation between stock market return and inflation is not entirely new in the financial literature, but has gained a higher momentum only very recently. A number of authors (see, e.g., Shiller and Beltratti, 1992; Smith, Sorensen and Wickens, 2003, 2006, among others) sought for a link between the mean of excess stock returns and inflation in the US and UK. Shiller et al. (1992) reported a negligible or moderately negative relation, whereas Smith et al. (2003, 2006) reported a changing nature of the time-varying correlation between the mean of excess stock returns and inflation (predominantly negative before 1998 and positive, thereafter). Lettau, Ludvigson and Wachter (2004) focused on fundamentals' volatility in order to explain the decline in the long-term equity risk premium in the 1990s and found that the Sharpe ratio depends linearly on the volatility of consumption. However, Brandt and Wang (2003) asserted that news about inflation clearly dominates news about consumption growth in accounting for time variation in relative risk aversion. Yet, they discarded the so-called 'proxy hypothesis', but admitted that investors irrationally fear unexpected increases in inflation ${ }^{1}$. Along similar

\footnotetext{
${ }^{1}$ The 'proxy hypothesis' formulated by Fama (1981) suggests that the estimated relation between risk aversion and inflation is misleading because it simply reflects the omitted variable bias, so long as inflation is correlated with an omitted real variable (such as future cash flows), which is in turn correlated with either risk aversion or
} 
lines, Campbell and Vuolteenaho (2004) extended the dynamic Gordon model for rational and irrational investors and found that inflation is positively correlated with rationally expected long-term real dividend growth, almost uncorrelated with the subjective risk premium, and is highly correlated with mispricing. While the findings in Campbell et al. (2004) are interesting, they cast doubt upon whether the equity risk premium and inflation are unrelated. A plausible explanation is that the channels implied by Campbell et al. (2004) and Lettau et al. (2004) do not reflect the existing relation between the two quantities.

We investigate in this paper whether stock market investors in UK and US significantly price the rate of inflation, which is thought to have real effect on the economy through inflation uncertainty. Our framework is similar to that in Smith et al. (2003, 2006), but different from that in Campbell et al. (2004) and Lettau et al. (2004). More specifically, we build our study upon the methodology of Scruggs (1998), who used a modified bivariate exponential generalised heteroskedasticity model-in-mean (EGARCH-M) in order to assess the two-tier riskreturn (also called 'convoluted') relation embracing the equity premium, stock market volatility, and interest rates. Our model departs from Scruggs (1998) in several important aspects. First, it incorporates inflation and output growth dynamics to explicitly capture inflationary expectations and output growth prospects. While our main focus is on inflation risk premia, we also control for economic growth factor as investors to assess risks of investment projects may use economic growth prospects. Second, this dynamics substantially complements investors' information set used to price assets and assess macroeconomic risks. Third, our model enables to address the question upon whether the documented persistent decline in macroeconomic volatility can be traced out by the expected risk premia. Fourth, we use long-term government bond yields to capture long-term inflationary expectations rather than for hedging of interest rate risk, as in Scruggs (1998).

These distinctive features of our model need to be further supported by the literature of empirical macroeconomics. This literature rationalises the link between macroeconomic volatility and the level of macroeconomic factors and provides evidence of the widespread and persistent decline in macroeconomic volatilities over the last 20 years or so.

Modelling EGARCH-M type heteroskedasticity of inflation and industrial production growth can be motivated by Friedman (1977) who argued that inflation uncertainty adversely affects the ability of price mechanism to allocate resources efficiently. Fischer (1981), Huizinga (1993) explored this idea was more formally. More recently, by Grier, Henry, Olekalns and Shields (2004), and Shields, Olekalns, Henry and Brooks (2005) have provided a piece of evidence that real asset prices through a different channel. 
inflation and industrial production monthly data have a tendency to cluster in certain periods and thus exhibit conditional heteroskedasticity. In addition, the literature of empirical finance (see, e.g., Glosten, Jagannathan and Runkle, 1993; Perez-Quiros and Timmermann, 2000) report significant links between stock market volatility and short-term interest rate that is thought to embody investors' expectations about future inflation.

We also address the question whether the observed moderation in macroeconomic volatilities (see, e.g., Stock and Watson, 2002; Kizys and Spencer, 2004) has been reflected in the equity risk premia. We do not pretend to explain this phenomenon. Instead, at this point, our objective is to examine whether the decreased macroeconomic uncertainty has been reflected in equity risk premia.

Our paper encompasses essentially four papers. Methodologically, it builds upon Smith et al. (2003, 2006) and Cappiello and Guene (2005). In Smith et al. (2003), the authors revisit the general equilibrium-based SDF models in the context of the UK and US equity markets. They find that the conditional variance between equity return and CPI inflation is significantly priced by equity market investors. In Smith et al. (2006), the authors, using a generalisation of the SDF model, seek to identify and explain the potential asymmetries in the volatility of equity returns, inflation, industrial production growth rate, and money growth rate. Cyclical behaviour of equity market volatility and asymmetric business-cycle effects on equity returns are also thought to have asymmetric effects on macroeconomic volatility. Again, Smith et al. (2006) find that the inflation risk premium is significantly priced by equity market investors. Although the conditional variances of equity market return and industrial production growth exhibit notable asymmetries, no asymmetric effect unexpected inflation appears to exert on the conditional variance of CPI inflation. Smith et al. (2006) reject the CAPM model in favour of a more general asset pricing model that includes macroeconomic factors, but is not implied by any particular theory. Because of this fact, we build, as in Smith et al. (2006), upon a generalised asset pricing model that contains CPI inflation and industrial production growth rate as rewardable macroeconomic risk factors.

Ideologically, our paper is motivated by Cappiello and Guene (2005). They used the VARMGARCH-M to model the inflation risk premium in bond and equity market returns in Germany and France within the intertemporal CAPM in the tradition of Merton (1973). In the Merton's intertemporal world, there is a scope for hedging demands against unfavourable shifts in investment opportunity set. Because of this hedging need, equilibrium expected equity returns on assets will depend not only on 'systematic' or 'market' risk (as in a traditional static CAPM), but also on 'intertemporal' risk. The intertemporal risk premium involves the covariance of eq- 
uity returns with the state variables. Because inflation can be thought to represent unfavourable shifts in investment opportunity set, the intertemporal risk premium can be proxied by the inflation risk premium. Cappiello and Guene (2005) find that the inflation risk premium may explain a significant proportion of the variability in the excess equity returns. It is also worth noting that in Cappiello and Guene (2005), the inflation risk premium is larger for long-term governmet bonds than short-term government bonds. This result is consistent with the notion that inflation is a more important macroeconomic source of risk in the long run than in the short run or, -put it differently-, is a long-run phenomenon. For this reason, we argue that it is long-term government bond yields that should be used to capture inflationary expectations, rather than short-term government bond yield.

Motivated by the above bodies of literature we ask ourselves whether macroeconomic volatilities significantly respond to changes in inflationary expectations and whether investors significantly price in these macroeconomic volatilities. As in Scruggs (1998), we focused on the convoluted relation between the equity risk premium, macroeconomic risk, and inflationary expectations. We postulated, as in Smith et al. (2003, 2006), the stochastic discount factor (SDF) model in order to rationalise the link between equity risk premia and macroeconomic factors embodied in the covariances of equity market returns with industrial production growth and with CPI inflation. We used monthly data for the period 1950:1 - 2004:12 (US) and for 1964:1 - 2004:12 (UK) in order to: first, re-examine the risk-return relation, second, to study the convoluted relation among the equity risk premium, macroeconomic and financial volatility, and long-term inflationary expectations, third, to assess effects of macroeconomic volatility decline on the equity risk premium. We estimated trivariate modified EGARCH-M models to trace out the direct impact that the long-rate government bond yields have on financial and macroeconomic volatilities, and indirect effect, on the equity risk premia. We found that the long-rate government bond yields exert a considerable direct impact on macroeconomic and financial volatilities, but that the indirect effect is less clear. We also analysed the implied risk premia for UK and US. We found that the US equity risk premium reflects the decline in macroeconomic volatilities over the sample period, while the UK equity risk premium follows a different pattern. A relatively less volatile period of the 1960s in UK was followed by a quite turbulent period in the 1970s, but in the 1980s and later the risk premium has declined again. Our research also implies that stock market investors should use a long-term government bond yield for the UK and the term spread for the US to instrument their assessment of stock market investment opportunities. In addition, we suggest that the relevance of the short-term interest rates has decreased over the last decade, whereas the relevance of the long-term government yields, in 
contrast, has increased.

Our findings are useful for practitioners and academics in several respects. First, they allow reassessing the risk-return relation by using a triangular-decomposition based multivariate EGARCH-M, which so far seldom has been used. Second, our results may be useful for stock market investors who form expectations on the basis of macroeconomic information to evaluate their investment opportunities. Third, the convoluted relation between the equity risk premia, macroeconomic and financial volatilities, and long-term government bond yields has not been studied yet in the literature. Fourth, we provide some evidence that the observed decline in macroeconomic volatilities in the 1980s was followed by the decrease in risk premia. Fifth, while our research contributes to the ongoing discussion on the risk-return relation, we observe that the sign, significance, and magnitude of this relation are model-dependent.

We organise our study as follows. In section 2, we set up SDF model of the equity risk premia. In Section 3, we formulate our empirical model. In Section 4, we describe data. In Section 5, we report our empirical results for UK and US and generate the implied risk premia. Finally, in section 6 , we offer some concluding remarks.

\section{The SDF Model of the Equity Premium}

To study the relation between the equity risk premium and macroeconomic volatilities, we used the generalised stochastic discount factor (SDF) model. The generalised SDF model provides a general framework for asset pricing, and is based on the no-arbitrage condition. The advantage of the generalised SDF model is that it does not require the knowledge about investors' preferences and allows for substantial flexibility in theorising the stochastic discount factor. For instance, Smith et al. (2006) reject the CAPM in favour of a more general asset-pricing model that includes additional macroeconomic factors, and is not implied by any particular theoretical model. Another advantage of the generalised SDF model is that it allows explicitly relating asset pricing to the variation in macroeconomic factors and is thus a standard approach in macro-finance. Because of these facts, we built upon a general SDF-based asset pricing model. As we show in the next section, the SDF class of models may be successfully used in a multivariate framework to model the joint distribution of the excess equity returns and macroeconomic factors. In fact, it is consistent with standard models of financial econometrics, such as multivariate GARCH, that may be used to generate the time-varying covariances. The time-varying covariances give rise to macroeconomic risk premia. The use and usefulness of the SDF models in finance and econometrics is surveyed by Smith and Wickens (2002). 
The stochastic discount factor (SDF) model is based on the notion that the price of an asset at the beginning of period $t, P_{t}$, is given by the expected (stochastically) discounted value of its payoff at the beginning of period $t+1, X_{t+1}$ :

$$
P_{t}=E_{t}\left[M_{t+1} X_{t+1}\right]
$$

where $M_{t+1}$ is the stochastic discount factor, and $X_{t+1}$ is defined as

$$
X_{t+1}=P_{t+1}+D_{t+1},
$$

where $D_{t+1}$ is a dividend payment to be received at the beginning of period $t+1$. Dividing Equation (1) by $P_{t}$ obtains:

$$
1=E_{t}\left[M_{t+1} \frac{X_{t+1}}{P_{t}}\right]=E_{t}\left[M_{t+1} R_{t+1}\right]
$$

where $R_{t+1}=1+r_{t+1}$ stands for the gross equity return $\left(r_{t+1}\right.$ is the net equity return) and is defined as

$$
R_{t+1}=1+r_{t+1}=\frac{P_{t+1}+D_{t+1}}{P_{t}}
$$

Assuming log-normality and taking logarithms of (3) gives:

$$
0=\ln E_{t}\left[M_{t+1} R_{t+1}\right]=E_{t}\left[\ln \left(M_{t+1} R_{t+1}\right)\right]+\frac{1}{2} V_{t}\left[\ln \left(M_{t+1} R_{t+1}\right)\right]
$$

Further operating yields:

$$
0=E_{t}\left(m_{t+1}\right)+E_{t}\left(r_{t+1}\right)+\frac{1}{2} V_{t}\left(m_{t+1}\right)+\frac{1}{2} V_{t}\left(r_{t+1}\right)+\operatorname{Cov}_{t}\left(m_{t+1}, r_{t+1}\right),
$$

where $m_{t+1}=\ln M_{t+1}$.

Equation (6) implies that the risk-free asset (such as Treasury Bill) can be priced according to:

$$
E_{t}\left(m_{t+1}\right)+r_{t}^{f}+\frac{1}{2} V_{t}\left(m_{t+1}\right)=0
$$

where $r_{t}^{f}$ is the rate of return on a risk-free asset. The expected equity premium can be obtained by subtracting Equation (7) from Equation (6) and rearranging terms:

$$
E_{t}\left(r_{t+1}-r_{t}^{f}\right)+\frac{1}{2} V_{t}\left(r_{t+1}\right)=-\operatorname{Cov}_{t}\left(m_{t+1}, r_{t+1}\right)
$$


Equation (8) tells us that the expected equity premium for an asset must satisfy the noarbitrage condition when its return and the SDF are log-normally distributed. The right-hand side is the expected equity premium, and $\frac{1}{2} V_{t}\left(m_{t+1}\right)$ is the time-varying Jensen effect arising from the assumed log-normality of the above variables.

Our task is to study the role of inflation in determining the risk premium. In general, the SDF model incorporates any potential source of risk into an explanation of the risk premium as long as the non-arbitrage condition is satisfied (Smith, et al., 2003). One way to introduce inflation in this framework is to assume that the stochastic discount factor can be expressed as a linear combination of a vector of macroeconomic factors, including inflation:

$$
-m_{t+1}=\beta^{\prime} z_{t+1}
$$

where $z_{t+1}$ denotes a vector of macroeconomic factors. Therefore, the no-arbitrage condition can now be written as:

$$
E_{t}\left(r_{t+1}-r_{t}^{f}\right)+\frac{1}{2} V_{t}\left(r_{t+1}\right)=\sum_{i=1}^{N} \beta_{i} \operatorname{Cov}_{t}\left(z_{i, t+1}, r_{t+1}\right) .
$$

Assuming that the only macroeconomic factors that affect the equity risk premium are the real industrial production growth rate $\triangle y_{t}$, and inflation $\pi_{t}$, the unrestricted version of Equation (10) can be expressed as:

$$
E_{t}\left(r_{t+1}-r_{t}^{f}\right)=\beta_{0} V_{t}\left(r_{t+1}\right)+\beta_{1} \operatorname{Cov}_{t}\left(\pi_{t+1}, r_{t+1}\right)+\beta_{2} \operatorname{Cov}_{t}\left(\triangle y_{t+1}, r_{t+1}\right) .
$$

In (11), the equity risk premium consists of two parts: the inflation risk premium defined by $\beta_{1} \operatorname{Cov}_{t}\left(\pi_{t+1}, r_{t+1}\right)$, and the industrial production growth risk premium, captured by $\beta_{2} \operatorname{Cov}_{t}\left(\triangle y_{t+1}, r_{t+1}\right)$. The exact direction of the relation between the equity risk premium and macroeconomic factors is determined by the sign of the parameters $\beta_{1}$ and $\beta_{2}$. The generalised SDF model does not place any restriction on these parameters. In the literature of macrofinance, a consensus on what sign, -positive or negative-, should the relation between equity risk premium and macroeconomic volatilities take on has not yet emerged. Although conventional wisdom suggests that equity market investors will require a higher reward on a higher inflation risk premium, Chen, Roll and Ross (1986) argued that since changes in inflation have the general effect of shifting wealth among investors, there is no a priori presumption that would sign the risk premia for inflation. The negative signs on equity risk premia would probably mean that equity market assets are generally perceived to be hedges against the adverse influence on other assets that are, presumably, more fixed in nominal terms. Along similar lines, Cappiello and 
Guene (2005) argued that, in the intertemporal world of Merton's (1973) tradition, there is a scope of hedging demands against unfavourable shifts in investment opportunity set. Because of this hedging need equilibrium expected returns on assets will depend not only on 'systematic' or 'market' risk (as in the traditional CAPM), but also on 'intertemporal' risks. The intertemporal risk premium is given by the covariance of equity returns with the state variables. Because inflation may be thought of to represent 'unfavourable' shifts in investment opportunity set, the intertemporal risk premium can proxied by the inflation risk premium.

\section{The Econometric Model}

In order to estimate the time-varying risk premium in (11), we seek for a specification which allows us to estimate jointly a time-varying variance and covariance matrix of excess returns, inflation and industrial production growth rate. As such, one can employ the multivariate EGARCH-M model in which the conditional mean of excess return equation is restricted by the non-arbitrage condition. The multivariate EGARCH-M model is structured in three equations: the conditional mean equation, the conditional variance equation, and the conditional covariance equation. The conditional mean equation written in a vector autoregression (VAR) form augmented with exogenous effects embodied in the time-varying variance and covariance matrix $\Sigma_{t}$ :

$$
Y_{t}=A+B Y_{t-1}+\Gamma \Sigma_{t}+u_{t}
$$

where $Y_{t}=\left(\triangle y_{t}, \pi_{t}, r_{t}-r_{t}^{f}\right)^{\prime}$ is a vector of variables belonging in a trivariate VAR, $u_{t}$ is distributed normally with zero mean vector and a (time-varying) conditional variance and covariance matrix $\Sigma_{t}$. The non-arbitrage condition requires that the third element of the parameter vector $A$ and the third row elements of the parameter matrix $B$ equal zero. In other words, in order to rule out the no-arbitrage condition, the constant term in the excess equity return equation is constrained to zero. Constraining the third row elements of $B$ to zero rules out lagged effects of the variables contained in the VAR. On the other hand, the third row of the coefficient matrix $\Gamma$ contains the time-varying Jensen effect and the time-varying covariances, whereas the other two rows are constrained to zero.

Multivariate volatility modelling involves time variation of $\Sigma_{t}$. In order to ensure positive definiteness of the time-varying conditional variance and covariance matrix a number of useful parameterisations have been proposed in the literature. A reparameterisation we adopt in this research is the triangular decomposition. This reparameterisation has several advantages over 
other reparameterisations. On the one hand, the triangular decomposition can be used to identify the sequence of residuals of the structural VAR. Remarkably, it underlies the identification scheme proposed by Sims (1980), who suggested obtaining a unique triangular decomposition of the residuals of the reduced-form VAR by imposing a specific ordering of the endogenous variables included in the VAR. Further, according to Tsay (2002), this approach has several advantages in that it requires no parameter constraints for the positive definiteness of $\Sigma_{t}$. In addition, the reparameterisation is an orthogonal transformation so that the resulting likelihood function is extremely simple. Because of the positive definiteness of $\Sigma_{t}$, there exists a lower triangular matrix $L_{t}$ with unit diagonal elements and a diagonal matrix $G_{t}$ with positive diagonal elements such that

$$
\Sigma_{t}=L_{t} G_{t} L_{t}^{\prime}
$$

This is the well-known triangular decomposition of $\Sigma_{t}$. As stated in Tsay (2002), an attractive feature of the decomposition is that the lower off-diagonal elements of $L_{t}$ and the diagonal elements $G_{t}$ have nice interpretations. In particular, in the three-dimensional case, in which

$$
L_{t}=\left(\begin{array}{ccc}
1 & 0 & 0 \\
q_{21, t} & 1 & 0 \\
q_{31, t} & q_{32, t} & 1
\end{array}\right), G_{t}=\left(\begin{array}{ccc}
g_{11, t} & 0 & 0 \\
0 & g_{22, t} & 0 \\
0 & 0 & g_{33, t}
\end{array}\right)
$$

the triangular decomposition of $\Sigma_{t}(13)$ implies

$\Sigma_{t}=\left(\begin{array}{ccc}\sigma_{11, t} & \sigma_{21, t} & \sigma_{31, t} \\ \sigma_{21, t} & \sigma_{22, t} & \sigma_{32, t} \\ \sigma_{31, t} & \sigma_{32, t} & \sigma_{33, t}\end{array}\right)=\left(\begin{array}{ccc}g_{11, t} & q_{21, t} g_{11, t} & q_{31, t} g_{11, t} \\ q_{21, t} g_{11, t} & q_{21, t}^{2} g_{11, t}+g_{22, t} & q_{31, t} q_{21, t} g_{11, t}+q_{32, t} g_{22, t} \\ q_{31, t} g_{11, t} & q_{31, t} q_{21, t} g_{11, t}+q_{32, t} g_{22, t} & q_{31, t}^{2} g_{11, t}+q_{32, t}^{2} g_{22, t}+g_{33, t}\end{array}\right)$

Henceforth, we call the elements $g_{i i, t}(i=1,2,3)$ time-varying structural variances ${ }^{2}$. Using the triangular decomposition to reparameterise $\Sigma_{t}$ has several attractive features. The most important feature is that $\Sigma_{t}$ is positive definite if $g_{i i, t}>0$ for each $t$. Consequently, to yield the positive definiteness of $\Sigma_{t}$ all we have to do is to impose constraint such that $g_{i i, t}>0$ for each $t$. We assume here that the time-varying structural variances are driven by the lagged long-term government yield that proxies for inflationary expectations (see, for instance, Kim and Nelson,

\footnotetext{
${ }^{2}$ By the same token, we call the elements $\sigma_{i i, t}(i=1,2,3)$ time-varying reduced-form conditional variances.
} 
1989; Glosten, Jaganathan and Runkle, 1993; Perez-Quiros and Timmermann, 2000, among others $)^{3}$.

As previously mentioned, we adopt the multivariate EGARCH-M specification, a univariate version of which was developed by Nelson (1991). As Scruggs (1998) notes, the EGARCH model constitutes a significant refinement of the GARCH model. Unlike the other functional forms of conditional heteroskedascitity, the exponential form of conditional variance ensures its positive definiteness and thus requires placing no constraints on parameters capturing ARCH and GARCH effects. Furthermore, in the last decade, the literature of empirical finance has strongly advocated using an EGARCH specification for volatility modelling, rather than squareroot or affine volatility models (see, e.g., Scruggs, 1998; Perez-Quiros and Timmermann, 2000; Adrian and Rosenberg, 2005, to mention just few). More specifically, Adrian et al. (2005) argue that an EGARCH model allows for more skewness in the distribution of volatility. Chernov, Gallant, Ghysels, and Tauchen (2003) compare a number of stochastic volatility models and find that exponential models perform better than affine models. In addition, EGARCH models seem to better accommodate the existence of extreme values in the financial data ${ }^{4}$.

Our model, if compared to Scruggs (1998), allows for a richer volatility dynamics and provides a scope for efficiency gains. In fact, we estimated a three-factor CAPM model within a restricted

\footnotetext{
${ }^{3}$ To account for expected inflation, some authors have been using the nominal interest rate. Glosten et al. (1993) argued that, to the extent that short-term nominal interest rates embody expectations about future inflation, they could be a good predictor of future volatility in excess returns. For the same reason, as a sole predictor of time-varying conditional variance of excess returns the short-term nominal interest rate was also used by Perez-Quiros and Timmermanm (2000). Kim and Nelson (1993) argued that the ARCH-type conditional volatility model is ad-hoc, since the existence of ARCH can sometimes be interpreted as evidence for misspecification. However, the empirical evidence suggests that the ARCH-type conditional volatility modeling appears to have done a good job in explaining time varying conditional volatilities.

${ }^{4}$ As an alternative model, we also used GJR (1993) model of asymmetric GARCH-M. We depart from Glosten et al. (1993), by including the lagged long-term bond yield $i_{t-1}$ as exogenous variable instead of the short-term Treasury bill rate:

$g_{i i, t}=\alpha_{i 0}+\alpha_{i 1} g_{i i, t-1}+\alpha_{i 2} v_{i, t-1}^{2}+\alpha_{i 3} v_{i, t-1}^{2} I_{i, t-1}+\alpha_{i 4} i_{t-1}, i=1,2,3 ;$

where $I_{i, t-1}=1$ if $v_{i, t-1}<0$, and $I_{i, t-1}=0$ if $v_{i, t-1}>0$, is an indicator variable which captures the leverage effect. Empirically, a negative stock price change increases stock market volatility by more than a positive stock price change. A decrease in today's stock price changes a firm's capital structure by increasing leverage. In order to ensure the positive-definiteness of the structural variances, we place non-negativity constraints on the parameters $\alpha_{i 0}, \alpha_{i 1}, \alpha_{i 2}, \alpha_{i 3}$. In order to the correct impact that the long-term government bond yield exerts on volatility, we do not restrict parameter $\alpha_{i 4}$, but rather allow the data to determine its sign. A drawback of the GJR approach is that for a given range of negative parameter values the conditional variance potentially may turn out to be negative, although Grier et al. (2004) argue that unexpected inflation tends to increase uncertainty of output growth.
} 
vector autoregression with exogenous terms and conditionally heteroskedastic errors. Similarly as in Glosten et al. (1993), Scruggs (1998), Perez-Quiros et al. (2000), our volatility model accounts for the observed relation between stock market volatility and the level of the nominal risk-free rate. It includes a long-term bond yield as exogenous variable which is thought to capture long-term inflationary expectations. For the US model, as a long-term bond yield we use the 15-year lagged Treasury bond yield, whereas, for the UK model we use the consol or perpetual yield. In this model, the conditional variances of output growth, inflation and excess returns are governed by:

$g_{i i, t}=\exp \left(\alpha_{i 0}+\alpha_{i 1} \ln \left(g_{i i, t-1}\right)+\alpha_{i 2} \frac{v_{i, t-1}}{\sqrt{g_{i i, t-1}}}+\alpha_{i 3}\left(\left|\frac{v_{i, t-1}}{\sqrt{g_{i i, t-1}}}\right|-\sqrt{\frac{2}{\pi}}\right)+\alpha_{i 4} i_{i, t-1}\right), i=1,2,3 ;$

where $i_{i, t-1}$ denotes the long-term government bond yield. The leverage effect can be decomposed into the sign effect, captured by the parameter $\alpha_{i 2}$, and the size effect, captured by the parameter $\alpha_{i 3}$. This is consistent with 3 stylised facts documented by Engle and $\mathrm{Ng}$ (1993). First, a negative shock increases stock market volatility more than a positive shock of equal magnitude, which is why we would expect $\alpha_{i 2}$ to be negative. Second, a large negative shock raises stock market volatility more than a small negative shock. Third, a large positive shock increases stock market volatility more than a small positive shock. Because of these size asymmetries, we would expect that $\alpha_{i 3}$ will take on positive values. Moreover, it includes the long-term bond yield as exogenous variable that is thought to capture long-term inflationary expectations. The use of the lagged level of the long-term government bond yield is intuitively appealing. Glosten et al. (1993) argued that, to the extent that short-term nominal interest rates embody expectations about future inflation, they could be a good predictor of future volatility in excess returns. For the same reason, as a sole predictor of time-varying conditional variance of excess returns the short-term nominal interest rate was also used by Perez-Quiros et al. (2000), which also entered exponentially in the conditional variance equation. Modelling inflation and output growth volatilities as a function of inflationary expectations owes to the Friedman's (1977) hypothesis and was further supported by Fischer (1981). The interpretation of the Friedman's hypothesis is two-fold. First, it implies that the increased variability of the level of inflation causes a reduction in the allocative efficiency of the price system, causing a reduction in natural level of output. Second, failure of coordination of monetary and fiscal policies leads to the increased variability of inflation when the central banks attempts to counter the increased level of inflation as a consequence of loose fiscal policy. The former interpretation implies that output variability 
may be driven by the level of inflation, whereas the latter reasoning implies that the volatility of inflation may depend upon the level of inflation.

Using the level of inflation is not entirely new in the literature of finance. Researchers often include the level of inflation in the investors' information set in order to account for pervasive, or 'systematic', as the likely source of adverse shifts in the investment opportunity set and thus the source of investment risk, as argue by Chen, Roll and Ross (1986). Also, Cappiello and Guene (2005) and the Merton's (1973) intertemporal world imply that the time-varying risk premium measures the exposure of an asset to the risk stemming from changes in the investment opportunity set. Hedging against adverse shifts in the investment opportunity set provides scope for the consumption-smoothing behaviour of investment. For instance, if an asset provides a good hedge against inflation, intertemporally maximising investors will attempt to smooth consumption over time by holding that asset in the periods of higher inflation. As result, the price of an asset will go up, and investors will be willing to accept lower rate of return in order to smooth consumption over time and hedge against inflation.

Modelling inflation and output growth uncertainty is supported by the theoretical and empirical literature. Very recently, the literature of empirical macroeconomics (see, e.g. Grier et al., 2004; Shields et al., 2005) has come up with some evidence on the asymmetric behaviour of output growth and inflation. For instance, unanticipated inflation tends to increase inflation uncertainty more than unanticipated deflation of equal magnitude. Therefore, for the conditional variance of inflation, we would expect $\alpha_{i 2}$ to be positive. As for the differential size effect, the estimated model in Grier et al. (2004) provides no indication, but the Positive size test performed by Shields et al. (2005) suggests important positive size asymmetries in the post-war data of US inflation. As for output growth uncertainty, Grier et al. (2004) find that unexpected decline in output growth raises output uncertainty more than unexpected increase which would imply a negative sign for the $\alpha_{i 2}$. The estimates in Grier et al. (2004) have no implication on what the differential size effect should be, but the analysis in Sields et al. (2005) suggests that both negative and positive size biases are present in the post-war data of industrial production growth rate. This predicts $\alpha_{i 3}$ to be significantly positive. In addition, Grier et al. (2004) find some important spillover effects between output growth and inflation volatilities. For instance, unanticipated inflation tends to increase output growth uncertainty, and an unanticipated decrease in industrial production growth increases inflation uncertainty more than an unanticipated increase. The former finding suggests that the parameter $\alpha_{i 4}$ should be positive in the equation governing uncertainty of output growth. In the conditional variance of excess returns, we should observe positive effects of inflationary expectations, as higher inflation is likely to increase the 
risk of investment.

To the best of our knowledge, the relation between output growth uncertainty, inflation uncertainty, and stock market volatility on the one hand, and the long-term inflationary expectations, on the other hand, has not been explored yet. While the level of inflation and short-term interest rate thought to capture investor's (unobserved) inflationary expectations exert a positive influence on uncertainty of inflation and output (see Glosten et al. 1993; Perez-Quiros et al., 2000, Grier et al., 2004), the literature is silent of what effect, -positive or negative-, should exert the long-term bond yield on uncertainty of inflation and output.

We do not explicitly model time-varying conditional covariances in this research. Instead, we choose to model the time-varying elements of the lower triangular matrix $L_{t}$ that are subsequently used to obtain time-varying correlations between the residuals of the VAR. One alternative is to use the constant-correlation assumption to estimate multivariate GARCH model developed by Bollerslev (1990). Although the constant-correlation assumption gives rise to a convenient multivariate GARCH model for estimation, many empirical studies find that this assumption is not supported by financial data, as noted by Engle (2002). In our framework, as Tse and Tsui (2002) argue, this assumption implies an implausibly strong restriction on data. To see this, consider the time-varying correlation between the first and second variables in the system

$$
\rho_{21, t}=\frac{\sigma_{21, t}}{\sqrt{\sigma_{11, t}} \sqrt{\sigma_{22, t}}} .
$$

Using the triangular decomposition of the time-varying variance and covariance matrix, we obtain:

$$
\rho_{21, t}=\frac{\sigma_{21, t}}{\sqrt{\sigma_{11, t}} \sqrt{\sigma_{22, t}}}=\frac{q_{21, t} \sigma_{11, t}}{\sqrt{\sigma_{11, t}} \sqrt{\sigma_{22, t}}}=q_{21, t} \frac{\sqrt{\sigma_{11, t}}}{\sqrt{\sigma_{22, t}}} .
$$

Observe that $\rho_{21, t}$ is time-varying unless it happens that $q_{21, t}=\rho \frac{\sqrt{\sigma_{22, t}}}{\sqrt{\sigma_{11, t}}}$ for a constant $\rho$. Further, expression (17) implies that the time-varying correlation between variables 1 and 2 in the system can be recovered from the structural quantities:

$$
\rho_{21, t}=q_{21, t} \frac{\sqrt{g_{11, t}}}{\sqrt{q_{21, t}^{2} g_{11, t}+g_{22, t}}} .
$$

One can show that $\rho_{21, t}$ can only take values between -1 and 1 . For simplicity's sake, we assume that the elements of the lower triangular matrix $L_{t}$ are constant: 


$$
q_{i j, t}=\varpi_{i j, 0},
$$

The ordering scheme we use to obtain the triangular decomposition of the time-varying variance and covariance matrix is as follows:

$$
Y_{t}=\left(\triangle y_{t}, \pi_{t}, r_{t}-r_{t}^{f}\right)^{\prime}
$$

The ordering of a set of time series in a VAR implies that a shock to a variable placed in a lower position of this ordering exerts no contemporaneous effect on the variables placed in a relatively higher position of this ordering. In contrast, a shock to a variable placed in a higher position of this ordering scheme exerts a contemporaneous effect on the variables placed in a relatively lower position if the ordering. We place the excess return in the lowest position of this ordering. This ordering captures the idea that financial markets may be forward looking and thus may instantaneously "react" if new information arrives at the market. If this is indeed the case, we can argue that the excess return should respond contemporaneously to all shocks hitting the VAR and should, in consequence, be placed in the lowest place of ordering of the endogenous variables in our VAR model. Furthermore, the Jensen effect (or the $(3,3)$ th element in matrix (14)) in the excess return equation, in addition to accounting for the time-varying stock market volatility, also contains the conditional variances of structural shocks to the GDP growth equation and to the CPI growth inflation. Thus, the macroeconomic variables are allowed to have a direct influence on the equity premium, through the time-varying covariances and indirect influence, by affecting the time-varying financial volatility.

One relevant issue with the GARCH-M models is genuinely econometric, related to the instability of the volatility effects in the conditional mean equation. In the review of ARCH models, Bollerslev, Chou and Kroner (1992) assert that GARCH-M parameters tend to be very unstable with respect to different model specifications. In addition, we find that the MLE estimation results of the EGARCH-M type models are also sensitive to initial parameter values. One of the plausible reasons is that all the parameters, those of conditional mean and of conditional variance, must be estimated simultaneously. In practice, choosing different initial values may lead to different parameter estimates because the parameters may not be identified. Further, because numerical optimisation algorithms have to iterate over the parameter products, in the absence of parameter restrictions there is an infinite number of parameter combinations leading to the same optimisation outcome. To see this, consider the conditional mean equation of stock return 


$$
r_{t+1}-r_{t}^{f}=\beta_{1}\left(q_{31, t}^{2} g_{11, t}+q_{32, t}^{2} g_{22, t}+g_{33, t}\right)+\beta_{2}\left(q_{31, t} q_{21, t} g_{11, t}+q_{32, t} g_{22, t}\right)+\beta_{3} q_{31, t} g_{11, t}+u_{3 t},
$$

where equity risk premium is defined by the sum of the second and the third components in the right hand side of the latter equation, whereas the first component represents the Jensen effect. Because the elements $q_{i j, t}$ are assumed constant, in what follows we suppress the time index $t$. We simplify further the conditional mean equation by grouping together the parameters of the respective structural variance $g_{i i, t}, i=1,2,3$.

$$
r_{t+1}-r_{t}^{f}=g_{11, t}\left(\beta_{1} q_{31}^{2}+\beta_{2} q_{31} q_{21}+\beta_{3} q_{31}\right)+g_{22, t}\left(\beta_{1} q_{32}^{2}+\beta_{2} q_{32}\right)+g_{33, t} \beta_{1}+u_{3 t} .
$$

Another reason for the instability of the EGARCH-M effects in the conditional mean equation is multicollinearity existing between time-varying covariances and the Jensen effect. To see this, recall that the time-varying structural variances $g_{i i, t}$ are modelled here as functions of the long-term government bond yield. The observed non-normality of the standardised residuals requires using quasi-maximum likelihood (QML) estimation. Under fairly weak assumptions (see Bollerslev and Wooldridge, 1992), the resulting estimates are consistent even when the conditional distribution of the residuals is non-normal. Robust standard errors are computed from the diagonal elements of the QML estimated of the variance and covariance matrix:

$$
E\left(\widehat{\theta}-\theta_{0}\right)\left(\widehat{\theta}-\theta_{0}\right)^{\prime} \cong T^{-1}\left(\Omega_{2 D} \Omega_{O P}^{-1} \Omega_{2 D}\right)^{-1},
$$

where $\widehat{\theta}$ denotes estimated parameter vector, $\theta_{0}$ denotes population parameter vector, $\Omega_{2 D}$ is the second-derivative estimation of the information matrix, $\Omega_{O P}$ is the outer product estimate of the information matrix.

\section{The Data}

In order to model equity risk premium in US and UK, we used a number of different sources of macroeconomic data. We downloaded monthly S\&P 500 stock index for the US from Thompson Financial Datastream. We obtained monthly FTSE 350 All Share Index from the Institute of Actuaries. David Miles from Morgan Stanley kindly provided us with the UK consol yield data. We also used the US Treasury discount bond yield data compiled by the New York Federal Bank. This data set has been extensively used in the empirical literature on the term structure. As there are some gaps in the long-term bond yield series we took the 15-year Treasury bond 
yield and filled gaps in with the longest available data. From the IMF IFS, we downloaded the industrial production data and the 3-Month Treasury bill rate data for US and UK, and the retail price index (RPI) data for UK. From The Observatorio de Coyuntura Económica Internacional (OCEI) of the Institute of International Economics (Valencia, Spain), we downloaded the US consumer price index data. As dictated by the data availability, for the US we used data sample spanning 1950:1-2004:12, whereas for the UK the data are available for 1964:1 - 2004:10. The data are summarised in Table 1.

- Insert Table 1 about here. -

\section{$5 \quad$ Estimation Results}

In the first step, we performed model selection for which purpose we used Schwarz Bayesian information criterion (BIC) to determine the optimal restricted order of vector autoregression in the conditional mean equation. The advantage of BIC is that it is designed to minimise the forecast error variance. In fact, as BIC penalises selecting a greater lag length, Luetkepohl (1991) strongly recommended avoiding fitting VAR models with unnecessarily great orders. Further, as in Luetkepohl (1991), we restricted the maximum VAR order to six in the model selection process, while keeping same specification for the conditional variance. Thus we assumed that the 6-lag length should capture well the dynamics of the model. Model selection results are given in Table 2.

- Insert Table 2 about here. -

In the US case, BIC selects three lags for the restricted VAR in the conditional mean equation, whereas for the UK case, one lag seems to be sufficient. Among other diagnostics, we report the autocorrelation test results for the $\operatorname{VAR}(1)$ to $\operatorname{VAR}(6)$ for each equation in the trivariate model (see Panel B of Table 2).

Estimation results for the selected model are available in Table $3^{5}$. In what follows, the model, which uses the long-term government bond yield as exogenous explanatory variable in

\footnotetext{
${ }^{5}$ We also estimated the GJR-type asymmetric model. We observe that the equity premium fell negative in the 1974s, if the GJR-type model for conditional variance is taken in consideration. This negative equity premium occurred during the recession caused by the first oil price shock. We do not exclude the possibility of the negative risk premium. This finding is consistent with hedging strategies of investors against, for instance, inflation jumps provoked by the supply-side shocks. However, the average monthly risk premium implied by the GJR model is only $0.13 \%$ (or $1.6 \%$ at annualised rate), which is difficult to reconcile with the stylised facts reported in the literature. The conditional covariances of the residuals from the equation of excess return with the residuals
} 
the conditional variance equation is referred as to Model 1.

- Insert Table 3 about here. -

We also analysed the model adequacy by means of a number of diagnostics. The diagnostics are given in Panels B and C. The trivariate modified EGARCH-M model seems to be reasonably well specified. Diagnostic The Engle and Ng (1993) Sign bias, Negative size bias, Positive size bias, and Joint tests (see Panel A) suggest no evidence of predictable components in squared standardised residuals that are related to volatility sign and size asymmetries. Likewise, Nelson (1991) specification tests (Panel B) suggest that orthogonality conditions are not, with few exceptions, significantly different from zero at $5 \%$ significance level. Notably, those few exceptions combined with the results of the Ljung-Box Q-tests (see Table 2) suggest that some autocorrelation structure in the equation for equity excess return for the US still persists. These tests also indicate that inflation in both countries the US and the UK follows a quite persistent process. Nevertheless, Bollerslev and Wooldridge (1992) robust QML estimation of the variance and covariance matrix of the parameters produces consistent standard errors when the model is possibly misspecified. The data generating process for output growth is less prone to misspecification. Overall, the trivariate EGARCH-M model fits the data quite well for the US and the UK.

\subsection{Conditional Mean Equation}

For further discussion of estimation results, we first consider the conditional mean model. Remarkably, in the conditional mean equations for industrial production growth rate and CPI inflation the parameter estimates appear to be relatively stable as compared to the estimates of the EGARCH-M effects in the conditional mean equation of excess return. We observe that for both UK and US, industrial production growth and inflation are essentially determined by the own lagged terms. Interestingly, we find that the lagged excess returns appear to be significant determinants of industrial production growth rate (US) and inflation (UK). As for the UK case, the lagged rate of inflation has a significantly negative impact on the industrial production growth rate.

from industrial production growth and CPI inflation are not significantly priced in the GJR model. However, the multivariate EGARCH-M model appears to perform better than the GJR model in terms of Schwarz BIC, which is another reason why we prefer to base our analysis on the EGARCH-M estimation. Moreover, for the EGARCH-M implied risk premium is always positive, which is more intuitive that the observed negative risk premium if the GJR-model is taken into consideration, and it dramatically increases in the 1974 in the aftermath of the first oil price shock. 


\subsection{Conditional Variance Equation}

The main interest of this research rests with the two-tier relation that involves the equity risk premia, financial and macroeconomic volatilities, and long-term inflationary expectations. This two-tier relation can be decomposed into two parts. The first-tier relation involves the relation between the conditional volatility and the long-term inflationary expectations captured by the long-term government bond yield. The second tier comprises the relation between the equity risk premia and financial and macroeconomic volatilities.

We first focus on the second-tier relation. In this relation, the lagged conditional variance is found statistically significant in all three equations for both countries, but in the US case, the conditional variance follows a more persistent process. The asymmetric sign effect, captured by the parameter $a_{i 2}$ is significantly negative for the conditional variance of industrial production growth (US) and equity return (UK and US), as expected. With regard to the equation for CPI inflation, we report positive inflation volatility sign effect for US and negative for UK, but in both cases the effects are imprecisely estimated. The inflation volatility sign effect is dominated by the volatility size effect, which is significantly positive for both the UK and US. This result is consistent with our previous discussion in Section 3 and implications by Grier et al. (2004) and Shields et al. (2005). As in the case with equity market volatility, the finding that large innovations to inflation (industrial production growth) have a greater impact on the conditional variance of CPI inflation (industrial production growth), of either sign, is not unreasonable.

Within the second-tier relation, we are specifically interested in the effect that the longterm government yield exerts on the conditional variances. Our discussion in Section 3 implies that the long-term government bond yield should exert a significantly positive influence. As for the UK, the long rate has significantly positive impact on the three conditional variances, as expected. There is no such a clear-cut evidence for the US. The long-term government bond yield counterintuitively exerts a negative effect on the conditional variance of industrial production growth, captured by the parameter $a_{i 4}$. It has a positive and marginally significant effect on the conditional variance of equity return, and a positive but insignificant effect on inflation uncertainty.

We examined these ambiguous effects of the US long-term government bond yield in more detailed. We looked at this relation from a different perspective. One of plausible reasons of why insignificant long-term government bond yield effect unfolds for the US is that US equity investors may be using different variables to instrument the rewardable inflation uncertainy. Specifically, we invoked a hypothesis that investors use term spread to quantify macroeconomic risk and instrument inflation risk premium of equity market investment. This possibility was 
pointed out to by Chen et al. (1986). The authors argued that the term spread can be interpreted as a change in the long-term interest rate. Alternatively, Hamilton and Kim (2002) interpret the term spread as the sum between the expected changes in the short-term interest rate and the term premium. Either way, the US equity market investors, rather than using absolute quantities to instrument the inflation risk premium, quantify macroeconomic risk with the expected changes in inflation. In our research, we define term spread as the difference between the long-term government bond yield and the short-term interest rate. Empirical evidence indicates that shortterm interest rates are countercyclical, whereas term spreads are procyclical. For instance, an unexpected increase in the short-term interest rate would temporarily flatten term structure and compress term spreads. Investment projects are more risky under the contractionary monetary policy stance, than under the expansionary one. Hamilton et al. (2002) conducted a survey on the predictive contents of the term structure and noted that the term structure is an excellent predictor of long-term economic growth and the probability of recession. Moreover, Hamilton et al. (2002) argued that if the current short-term interest rate is higher than the expected future short-term interest rate, then the long-term rate should rise less than the short-term rate according to the expectations hypothesis, which implies that the yield spread will be flattened. Therefore, we would expect a negative relation between the conditional volatilities of industrial production growth rate, inflation, and stock return on the one hand, and term spread, on the other hand. By the same token, this result would translate into a positive effect of long-term government bond yield and a negative effect of the short-term interest rate. We reestimated our modified model for US including both the short-term government yield and the long-term interest rate and found that these effects are indeed as conjectured, significantly positive for the long-term interest rate, and negative for short-term interest rate. The resulting model is referred to as Model 2. Estimation results are documented in Table 4.

- Insert Table 4 about here. -

We ran a similar exercise for UK, but estimation results turned out to be different from those of US. We also estimated modified EGARCH-M models for both countries using the term spread, computed as the difference between the long-term nominal government yield and shortterm nominal interest rate, and found that the term spread has a significantly negative effect for US, but an insignificant effect for UK. For further reference, the resulting model is called Model 3. Estimation results of Model 3 are available in Table 5.

- Insert Table 5 about here. - 
Finally, to establish a link with the existing literature, especially with Chen (1991), Glosten et al. (1993), Scruggs (1998), and Perez-Quiros et al. (2000), we estimated modified EGARCH$\mathrm{M}$ models in which we use short-term interest rate in financial and macroeconomic volatility modelling. The corresponding model is Model 4. Table 6 shows estimation results of Model 4 .

- Insert Table 6 about here. -

The short-term interest rate has a significantly positive effect on the conditional equity market variance in US, but it does not have a significant effect on the conditional variances of output growth and inflation. With regard to the UK model, we observe a strong relation of the short-term interest rate with the conditional variance of industrial production growth and inflation, but not with the conditional variance of equity return. Interestingly, as Model 2 indicates, when the long-term government bond yield is also included, the effects that the shortterm interest rate alone exerts on the conditional variances of industrial production growth rate and inflation become insignificant. This suggests that the UK equity market investors clearly prefer long-term financial instruments to short-term financial instruments in assessing macroeconomic sources of investment risk. With regard to US, there is no such a clear-cut evidence. As a matter of fact, the US equity market investors prefer to use a combination of financial instruments, either both long-term government bond yield and short term interest rate or term spread. Using either long-term government yield or short-term interest rate alone renders the relation between macroeconomic uncertainty and inflationary expectations either counterintuitive or insignificant. These findings may be considered as an indication that in the US, equity market investors may have become more risk tolerant when the economy is strong, because well-being is determined by their inflationary expextations relative to current inflation or, put it differently, by changes in the absolute level of inflation rather than by the absolute level of inflation. To check whether this is indeed the case, we reestimated our Model 4 for the sample size 1950:6 - 1994:12, similar to that used by Scruggs (1998). The estimation results indicate that the short-term interest rate for the US has a significant effect on all the conditional variances which confirms our previous conjecture ${ }^{6}$.

\subsection{Risk Premia}

We next focus on the risk premium-volatility relation. The estimation results available in Table 3 indicate that there is a positive relation between the UK equity excess return and inflation risk premium, which implies that investors will require a larger premium for investment with

\footnotetext{
${ }^{6}$ Estimation results are available from authors upon request.
} 
higher inflation uncertainty. The risk premia in all other cases are found insignificant. Although the theory predicts a positive relation between the market risk premium and conditional market variance, provided that investors are risk averse, the insignificance of the results is not surprising, as a vast number of empirical studies have documented similar results to ours. At this point, Scruggs (1998) provides a survey on the empirical literature on the risk-return relation, which clearly indicates that consensus has not been reached yet. Although Scruggs (1998) comes up with a positive relation, our research indicates that the sign, significance, and magnitude of this relation are model dependent.

Nevertheless, the very recent developments in the underlying literature are interesting and promising. For instance, Adrian et al. (2005) decompose the volatility of stock returns into short-term and long-term volatility components and analyse their risk premia. They show that the short-term component is associated with stock market liquidity, whereas the long-run component is closely linked to the business cycle. Their results indicate that investors negatively price both component, but the price of risk related to the long-term component is ten times as large as the price of risk related to the short-run component. Thus, one of the reasons would is that the risk premia we conceptualise in our model could be an interaction of the short-term and long-term volatility components and thus, in order to correctly assess the price of risk, the risk premia should be analysed from two perspectives. The first perspective should be related to macroeconomic variables, as in our approach, whereas the second perspective could with the short-term and long-term volatility components, as in Adrian et al. (2005).

The implied equity premium is given by

$$
\widehat{\phi}_{t}=\widehat{\gamma}_{31} \widehat{\operatorname{Cov}}_{t-1}\left(\triangle y_{t}, r_{t}\right)+\widehat{\gamma}_{32} \widehat{\operatorname{Cov}}_{t-1}\left(\pi_{t}, r_{t}\right)
$$

where $\widehat{\gamma}_{31}$ and $\widehat{\gamma}_{32}$ is the $(3,1)$ th and $(3,2)$ th elements of the parameter matrix $\Gamma$, respectively, $\widehat{\operatorname{Cov}}_{t-1}\left(\triangle y_{t}, r_{t}\right)$ and $\widehat{\operatorname{Cov}}_{t-1}\left(\pi_{t}, r_{t}\right)$ are estimated time-varying conditional covariances of the excess returns with industrial production growth rate and CPI inflation, respectively. Having estimated the model, we generated the implied equity premium series over the sample period for the US (time span covers 1951:1 - 2004:12), and for the UK (sample runs from 1964:3 to 2004:10) for the EGARCH-M model. The average monthly risk premia are $0.72 \%$ and $0.65 \%$ ( $8.64 \%$ and $7.80 \%$ per annum) for US and UK, respectively. The implied risk premia series are drawn in Figure 1.

- Insert Figure 1 about here. -

We observe that risk premia in general decreased over the sample period implying that 
today investors would demand lower premium for the same amount risk than say 50 years ago. Interestingly, for the case of US we can clearly identify two subsamples, one before and one after the early 1980s. This result encourages us to think that a lower and less volatile risk premium in the last 2 decades in the US can be attributed to a significant increase in macroeconomic volatilities in the early eighties, extensively documented in the literature of empirical macroeconomics. The right graph in Panels A and B depicts risk premia shares due to the time-varying covariance between output growth and stock return and covariance between inflation and stock return. The UK risk premium also appears to decrease towards the end of the sample, but it features an impressive hike in February 1974, in the aftermath of the oil price shock. As this extreme value alone shapes the time variation in the UK risk premium, we examined in more detail the causes of such a huge spike that almost reached $13 \%$ per month. Remarkably, the data suggest that in January 1974 the UK economy slumped by $4 \%$ as compared with the previous month, possibly due to the oil price shock that seemed to have in subsequent months a considerable effect on both industrial production and inflation, a phenonomen described my macroeconomists as "stagflation". However, the decomposition of the equity risk premium into the output growth and inflation based risk premia suggests that the observed spike is essentially due to the time-varying covariance between inflation and equity return, compounded by the fact that UK equity market investors significantly price inflation risk premium.

An important constituent of the risk premia are conditional variances, as Equation (22) indicates. Conditional variances are depicted in Figure 2.

- Insert Figure 2 about here. -

It is evident that the implied risk premia plot in Figure 1 shows some of the features of the time variation in conditional variances depicted in Figure 2. More specifically, the UK risk premium resembles very much the time variation in the conditional variance of CPI inflation, whereas the US equity risk premium reflects the persistent decline in output growth volatility.

Furthermore, it is interesting to observe the difference in the time variation in conditional correlations, depicted in Figure 3, across UK and US.

- Insert Figure 3 about here. -

We observe a positive, albeit low in magnitude, time-varying correlation between output growth and inflation in US, and positive but much more volatile in UK. Thus the sign of this correlation is as predicted by Phillips curve, although, not necessarily supported by the empirical 
evidence. Moreover, as Smith et al. (2006) argue, this is true only when a given business cycle phase is due to a demand shock. However, a recession due to a supply shock is likely to have higher than lower inflation, which implies a negative relation between output growth and inflation. We further observe a positive but low in magnitude time-varying correlation between output growth and stock return for US, and negative but low in magnitude timevarying correlation is UK. While the sign of the former correlation is intuitive, the sign of latter is far more difficult to interpret. Finally, because low returns and low inflation are expected in recession, we should observe a positive correlation between these two variables. However, this is true for UK, whereas this time-varying correlation is negative for the US.

\section{Conclusions}

In this paper, we used multivariate modified EGARCH-M models to assess the link between equity risk premia and macroeconomic volatilities. To rationalise this link equity risk premia and macroeconomic volatilities, we built our empirical study on the SDF model. One of the distinctive features of our empirical model is the triangular-decomposition based modelling of structural conditional variances and dynamic conditional correlations. As an innovative feature of our empirical model, we used long-term government bond yields in order to explain this riskreturn relation. To establish a link with the previous literature on empirical macroeconomics and finance, we also used a combination of the long-term government bond yield and the short-term interest rate, and the short-term interest rate alone in modelling of the conditional variances.

Our research suggests that stock market investors should use long-term government bond yield for the UK and term spread for the US in order to instrument their assessment of stock market investment opportunities and riskiness. Another important piece of evidence stemming from our research suggests that the relevance of the short-term interest rates has decreased over the last decade, while the relevance of the long-term government bond yields, in contrast, has increased. As a matter of fact, in contrast to Campbell (1987), Breen et al. (1989), Shanken (1990), Glosten et al. (1993), and Scruggs (1998), our research does not imply a significantly positive relation between conditional variances and the nominal short-term Treasury bill rate.

With regard to the risk-return relation, we found the UK investors tend to significantly price inflation risk premia (Model 1), whereas the other risk premia components are imprecisely estimated. One of the inherent characteristics of GARCH-M family models we emphasised in our discussion is that they tend to produce model-sensitive results.

The implied risk premia series are also noteworthy. Although risk premia are not significantly 
estimated, the implied pattern of fitted series strongly suggests that the decline in macroeconomic volatilities might have played an increasingly important role in reducing risk premia and its volatility in the US. While the same conclusion may not be deemed valid for the UK, we still observed the expected risk premia has somewhat decreased after the macroeconomic turbulence caused by the oil price shocks in the first half of the 70s.

Our research contributes to ongoing debate on the risk-return relation and may help to develop a deeper understanding of this relation.

\section{$7 \quad$ References}

Abel, A.B. (1994). 'Exact solutions for expected rates of return under Markov regime switching: implications for the equity premium', Journal of Money, Credit, and Banking, vol. 26, pp. 345361.

Abel, A.B. (1999). 'Risk premia and term premia in general equilibrium', Journal of Monetary Economics, vol. 43, pp. 3-33.

Adrian, T. and J. Rosenberg (2005). 'Stock returns and volatility: pricing the long-run and short-run components of market risk', mimeo, Federal Reserve Bank of New York.

Bollerslev, T., R.Y. Chou, K.F. Kroner (1992). 'ARCH modeling in finance', Journal of Econometrics, vol. 52, pp. 5-59.

Bollerslev, T., J.M. Wooldridge (1992). 'Quasi-maximum likelihood estimation and inference in dynamic models with time-varying covariances', Econometric Reviews, vol. 11 (2), pp. 143172 .

Boudoukh, J., M. Richardson (1993). 'Stock returns and inflation: a long horizon perspective', The American Economic Review, vol. 83 (5), pp. 1346-1355.

Brandt, M.W., K.Q. Wang (2003). 'Time-varying risk aversion and unexpected inflation', Journal of Monetary Economics, vol. 50, pp. 1457-1498.

Breen, W., L.R. Glosten, R. Jagannathan (1989). 'Economic significance of predictable variations in stock index returns', Journal of Finance, vol. 44 (5), pp. 1177-1189.

Campbell, J.Y. (1987). 'Stock returns and the term structure', Journal of Financial Economics, vol. 18, pp. 373-399.

Campbell, J.Y. (1996). 'Understanding risk and return', Journal of Political Economy, vol. 104 (2), pp. 298-345.

Campbell, J.Y., M. Lettau (1999). 'Dispersion and volatility in stock returns: an empirical investigation', NBER Working Paper No. 7144, Cambridge, MA, US. 
Campbell, J.Y., J. Ammer (1993). 'What moves the stock and bond markets? A variance decomposition for long-term asset returns', The Journal of Finance, vol. 48 (1), pp. 3-37.

Campbell, J.Y., A.W. Lo, A.C. MacKinlay (1997). 'The econometrics of financial markets', Princeton University Press, Princeton, NJ, US.

Campbell, J.Y., R.J. Shiller (1988a). 'Stock prices, earnings, and expected dividends', Journal of Finance, vol. 43 (July), pp. 661-676.

Campbell, J.Y., R.J. Shiller (1988b). 'The dividend-price ratio and expectations of future dividends and discount factors', The Review of Financial Studies, vol. 1, pp. 195-227.

Campbell, J.Y., T. Vuolteenaho (2004). 'Inflation illusion and stock prices', NBER Working Paper No. 10263, Cambridge, MA.

Cappiello, L., S. Guene (2005). 'Measuring market and inflation risk premia in France and in Germany', ECB Working paper No. 43, Frankfurt, Germany.

Chen, N.-F. (1991). 'Financial investment opportunities and the macroeconomy', Journal of Finance, vol. 46 (2), pp. 529-554.

Chen, N.-F., R. Roll, S.A. Ross (1986). 'Economic forces and the stock market', The Journal of Business, vol. 59 (3), pp. 383-403.

Chernov, M., R. Gallant, E. Ghysels and G. Tauchen (2003). 'Alternative models for stock price dynamics', Journal of Econometrics, vol. 116, pp. 225-257.

Donaldson, J.B., T. Johnsen and R. Mehra (1990), 'On the Term Structure of Interest Rates', Journal of Economic Dynamics and Control, vol. 14, pp. 571-596.

Journal of Economic Dynamics and Control, 14, 571-596.

Engle, R. (2002). 'Dynamic conditional correlation: a simple class of multivariate generalized autoregressive conditional heteroscedasicity models', Journal of Business $\&$ Economic Statistics, vol. 20 (3), pp. 339-350.

Engle, R., V. Ng (1993). 'Measuring and testing the impact of news on volatility', Journal of Finance, vol. 48 (5), pp. 1749-1778.

Engle, R., D.V. Lilien and R.P. Robins (1987). 'Estimating time varying risk premia in the term structure: the ARCH-M model', Econometrica, vol. 50, pp. 391-407.

Fama, E.F. (1981). 'Stock returns, real activity, inflation, and money', American Economic Review, vol. 71, pp. 545-565.

Ferson, W.E., C.R. Harvey (1991). 'The variation of economic risk premiums', Journal of Political Economy, vol. 99 (2), pp. 385-415.

Fischer, S., R.E. Hall, J.B. Taylor (1981). 'Relative shocks, relative price variability, and inflation', Brookings papers on economic activity, vol. 1981 (2), pp. 381-441. 
Friedman, M. (1977). 'Nobel Lecture: Inflation and Unemployment', Journal of Political Economy, vol. 85, pp. 451-472.

Froemmel, M. (2004). 'Modelling exchange rate volatility in the run-up to EMU using a Markov switching GARCH model, mimeo, University of Hannover, Discussion paper No. 303.

Glosten, L.R., R. Jagannathan, D.E. Runkle (1993). 'On the relation between the expected value and the volatility of the nominal excess return on stocks', The Journal of Finance, vol. 48 (5), pp. 1779-1801.

Grier, K.B., O.T. Henry, N. Olekalns, and K. Shields (2004). 'The asymmetric effects of uncertainty on inflation and output growth', Journal of Applied Econometrics, vol. 19, pp. $551-565$.

Hamilton, J.D. (1989). 'A new approach to the economic analysis of nonstationary time series and the business cycle', Econometrica, vol. 57 (March), pp. 357-384.

Hamilton, J.D. (1994). 'Time Series Analysis', Princeton University Press, Princeton, NJ, US.

Hamilton, J.D., D.H. Kim (2002). 'A reexamination of the predictability of economic activity using the yield spread', Journal of Money, Credit, and Banking, vol. 34 (2), pp.340-360.

Hamilton, J.D., G. Lin (1996). 'Stock market volatility and the business cycle', Journal of Applied Econometrics, vol. 11 (5), pp. 573-593.

Hamilton, J.D., R. Susmel (1994). 'Autoregressive conditional heteroskedasticity and changes in regime', Journal of Econometrics, vol. 64, pp. 307-333.

Huizinga, J. (1993). 'Inflation uncertainty, relative price uncertainty, and investment in U.S. manufacturing', Journal of Money, Credit, and Banking, vol. 25 (3), pp. 521-549.

King, M., E. Sentana and S. Wadhwani (1994). 'Volatility and links between national stock markets', Econometrica, vol. 62 (4), pp. 901-933.

Kizys, R., P. Spencer (2004). 'Equity valuation and macroeconomy: a project', mimeo, Department of Economics \& Related Studies, University of York, York, UK.

Lettau, M., S.C. Ludvigson (2001). 'Resurrecting the (C)CAPM: a cross sectional test when risk premia are time-varying', Journal of Political Economy, vol. 109 (6), pp. 1238-1287.

Lettau, M., S.C. Ludvigson (2004). 'Expected returns and expected dividend growth', Journal of Financial Economics, forthcoming.

Lettau, M., S.C. Ludvigson, J.A. Wachter (2006). 'The declining equity premium: what role does macroeconomic risk play?', mimeo, New York University and NBER, US.

Lintner, J. (1965). 'The valuation of risk assets and the selection of risky investments in stock portfolios and capital budgets', Review of Economics and Statistics, vol. 47, pp. 13-37. 
Luetkepohl, H. (1991). 'Introduction to multiple time series analysis', Springer-Verlag Berlin, Heidelberg, Germany.

Merton, R.C. (1973). 'An intertemporal asset pricing model', Econometrica, vol. 44, pp. 867-888.

Modigliani, F., R. Cohn (1979). 'Inflation, rational valuation, and the market', Financial Analysts' Journal. March-April, pp. 24-44.

Nelson, D. (1991). 'Conditional heteroskedasticity in asset returns: a new approach', Econometrica, vol. 59, pp. 347-370.

Perez-Quiros, G., A. Timmermann (2000). 'Firm size and cyclical variations in stock returns', Journal of Finance, vol. 60 (3), pp. 1229-1262.

Ravenna, F. and J. Seppala (2005).'Monetary policy and the term structure of interest rates', mimeo, Department of Economics, University of California, Santa Cruz, CA.

Roll, R., S.A. Ross (1980). 'An empirical investigation of the Arbitrage Pricing Theory', Journal of Finance, vol. 35 (3), pp. 1073-1103.

Rotemberg, J.J. and M. Woodford (1997). 'An optimization-based econometric framework for the evaluation of monetary policy', NBER Macroeconomics Annual, pp. 297 - 346.

Schwert, G.W. (1989). 'Why does stock market volatility change over time?', Journal of Finance, vol. 44, pp. 1115-1153.

Scruggs, J.T. (1998). 'Resolving the puzzling intertemporal relation between the market risk premium and conditional market variance: a two factor approach', Journal of Finance, vol. 53 (2), pp. 575-603.

Shanken, J. (1990). 'Intertemporal asset pricing', Journal of Econometrics, vol. 45, pp. $99-120$.

Sharpe, W.F. (1964). 'Capital asset prices: a theory of market equilibrium under conditions of risk', Journal of Finance, vol. 19, pp. 425-442.

Shields, K.K., N. Olekalns, Ó.T. Henry, and C. Brooks (2005). 'Measuring the tesponse of macroeconomic uncertainty to shocks'. Review of Economics and Statistics, vol. 87(2), pp. 362-370.

Shiller R.J., A.E. Beltratti (1992). 'Stock prices and bond yields. Can their comovements be explained in terms of present value models?', Journal of Monetary Economics, vol. 30, pp. $25-46$.

Sims, C. (1980). ' Macroeconomics and reality', Econometrica, vol. 48, pp. 1-49.

Smith, P.N., S. Sorensen, M.R. Wickens (2003). 'Macroeconomic sources of equity risk', mimeo, Department of Economics \& Related Studies, University of York, York, UK. 
Smith, P.N., S. Sorensen, M.R. Wickens (2006). 'The asymmetric effect of business cycle on the relation between stock market returns and their volatility, mimeo, Department of Economics \& Related Studies, University of York, York, UK.

Spencer, P. (2004a). 'Affine macroeconomic models of the term structure of interest rates: the US Treasury market 1961-99', Discussion Paper No. 2004/16, Department of Economics \& Related Studies, University of York, York, UK, web http://www.york.ac.uk/depts/econ/dp/0416.pdf.

Spencer, P. (2004b). 'An arbitrage-free macroeconomic model of the UK gilt-edged bond market 1979-2004', mimeo, Department of Economics \& Related Studies, University of York, York, UK.

Spencer, P. (2005a). 'What does the bond market tell us about the operation of UK monetary policy since 1979', Discussion Paper No. 2005/26, Department of Economics \& Related Studies, University of York, York, UK, web http://www.york.ac.uk/depts/econ/dp/0526.pdf.

Spencer, P. (2005b). 'An admisible macro-finance model of the US Treasury market 19632004', mimeo, Department of Economics \& Related Studies, University of York, York, UK.

Stock, J.H., M.W. Watson (2002). 'Has the business cycle changed and why?', NBER Working Paper No. 9127, Cambridge, MA, US.

Tsay, S.R. (2002). 'Analysis of Financial Time Series', Wiley, New York.

Tse, Y.K. and A.K.C. Tsui (2002). 'A Multivariate Generalized Autoregressive Conditional Heteroscedasticity Model With Time-Varying Correlations', Journal of Business and Economic Statistics. vol. 20, pp. 351-362.

Wickens, M.R., P.N. Smith (2001). 'Macroeconomic sources of FOREX risk, mimeo, Department of Economics \& Related Studies, University of York, York, UK. 


\section{Table 1 - Summary Statistics}

In this table, we provide a number of summary statistics of the continuously compounded monthly US and UK industrial production growth rates, rates of CPI and RPI inflation, and excess returns of S\&P500 and FT530 All Share indices we use in our empirical analysis. Kurtosis represents excess kurtosis over its value 3 under the case of normal distribution. $\mathrm{Q}(\mathrm{y}, 12)$ denotes the $\mathrm{p}$-value of a Ljung-Box Q-test for autocorrelation of order 12 in a given series. $\mathrm{Q}\left(\mathrm{y}^{2}, 12\right)$ denotes the $\mathrm{p}$-value of a Ljung-Box Q-test for autocorrelation of order 12 in a given squared series. JB denotes the $\mathrm{p}$-value of a Jarque-Bera test for normality of the unconditional returns distribution.

\begin{tabular}{|c|c|c|c|c|c|c|c|}
\hline & \multirow{3}{*}{$\begin{array}{l}\text { Country } \\
\text { Statistic }\end{array}$} & \multicolumn{3}{|c|}{ US } & \multicolumn{3}{|c|}{ UK } \\
\hline & & IP & CPI & Excess & IP & $\mathrm{CPI}$ & Excess \\
\hline & & Growth & Inflation & Return & Growth & Inflation & Return \\
\hline & & \multicolumn{6}{|c|}{ Conditional mean } \\
\hline 1 & Mean & 0.2894 & 0.3180 & 0.5265 & 0.1101 & 0.5339 & 0.3076 \\
\hline 2 & Median & 0.3073 & 0.2612 & 0.7315 & 0.1375 & 0.4224 & 0.8865 \\
\hline 3 & Maximum & 6.2310 & 1.7938 & 10.7609 & 9.4520 & 4.2186 & 43.2787 \\
\hline 4 & Minimum & -3.6081 & -0.5484 & -13.6007 & -8.1780 & -0.9383 & -31.3666 \\
\hline 5 & Std. Dev. & 0.9715 & 0.3132 & 3.4435 & 1.4223 & 0.6506 & 5.7100 \\
\hline 6 & Skewness & 0.4444 & 1.0990 & -0.7237 & -0.1956 & 1.9651 & 0.1231 \\
\hline 7 & Excess Kurtosis & 5.4888 & 2.3981 & 1.9748 & 10.4898 & 6.8199 & 8.8757 \\
\hline \multirow[t]{2}{*}{9} & $\mathrm{Q}(\mathrm{y}, 12)$ & 214.550 & 1984.97 & 52.7578 & 36.2038 & 730.292 & 22.1883 \\
\hline & (p-value) & $(0.0000)$ & $(0.0000)$ & $(0.0000)$ & $(0.0003)$ & $(0.0000)$ & $(0.0355)$ \\
\hline \multirow[t]{2}{*}{10} & $\mathrm{Q}\left(\mathrm{y}^{2}, 12\right)$ & 106.467 & 1565.73 & 35.0568 & 98.1759 & 268.901 & 60.7658 \\
\hline & (p-value) & $(0.0000)$ & $(0.0000)$ & $(0.0005)$ & $(0.0000)$ & $(0.0000)$ & $(0.0000)$ \\
\hline \multirow[t]{2}{*}{11} & JB (p-value) & 848.918 & 290.566 & 164.615 & 2249.70 & 1264.96 & 1609.60 \\
\hline & & $(0.0000)$ & $(0.0000)$ & $(0.0000)$ & $(0.0000)$ & $(0.0000)$ & $(0.0000)$ \\
\hline 12 & Observations & 659 & 659 & 659 & 490 & 490 & 490 \\
\hline
\end{tabular}

Table 2 - Model Selection

This table selects the model. Modified EGARCH-M models of the conditional variance are estimated for the US and UK. Models for the UK conditional volatility are estimated using sample 1964:1 - 2004:12. Models for the US conditional volatility are estimated using sample 1950:1 - 2004:12. The triangular decomposition of the variance and covariance matrix is performed in order to identify structural innovations. Output growth is ordered first, inflation is ordered second, and excess return third. The Schwarz Bayesian Information Criterion (BIC) is used to determine the optimal lag length for the restricted vector autoregressions (VARs) in the conditional mean equation (see Panel A). VAR(1) and VAR(3) are selected and fitted for the UK and the US, respectively. In Panel B, autocorrelation tests for the standardised residuals and squared standardised residuals are pursued for lags 1 to 6 in order to check given model adequacy. Panels B1 and B2 show autocorrelation test results for the equation of industrial production growth. Panels B3 and B4 show autocorrelation test results for the equation of inflation. Panels B5 and B6 show autocorrelation test results for the equation of excess returns.

Panel A - Information Criteria

\begin{tabular}{cccccccc}
\hline \hline & Country & \multicolumn{3}{c}{ US } & & UK & \\
\hline & Specification & LogL & AIC & BIC & LogL & AIC & BIC \\
\hline 1 & VAR(1) & -575.4691 & 1.8485 & 2.0473 & -1265.2810 & 5.3044 & 5.5535 \\
2 & VAR(2) & -549.2060 & 1.7838 & 2.0235 & -1261.0440 & 5.3226 & 5.6236 \\
3 & VAR(3) & -527.1957 & 1.7376 & 2.0187 & -1252.0798 & 5.3213 & 5.6745 \\
4 & VAR(4) & -510.3288 & 1.7070 & 2.0295 & -1247.3099 & 5.3374 & 5.7428 \\
5 & VAR(5) & -497.2987 & 1.6680 & 2.0522 & -1231.2907 & 5.3070 & 5.7649 \\
6 & VAR(6) & -478.9527 & 1.6527 & 2.0586 & -1205.1950 & 5.2348 & 5.7454 \\
\hline \hline
\end{tabular}


Panel B - Autocorrelation Tests

\begin{tabular}{|c|c|c|c|c|c|c|c|}
\hline & \multirow{3}{*}{$\begin{array}{c}\text { Equation } \\
\text { Country } \\
\text { Specification }\end{array}$} & \multicolumn{6}{|c|}{ B.1. Standardised residuals of output equation } \\
\hline & & \multicolumn{3}{|c|}{ US } & \multicolumn{3}{|c|}{ UK } \\
\hline & & $\mathrm{Q}(4)$ & $\mathrm{Q}(8)$ & $\mathrm{Q}(12)$ & $\mathrm{Q}(4)$ & $\mathrm{Q}(8)$ & $\mathrm{Q}(12)$ \\
\hline 1 & VAR(1) & $\begin{array}{l}17.8802 \\
(0.0013)\end{array}$ & $\begin{array}{l}22.5756 \\
(0.0040)\end{array}$ & $\begin{array}{l}27.4298 \\
(0.0067)\end{array}$ & $\begin{array}{c}7.1746 \\
(0.1269)\end{array}$ & $\begin{array}{l}14.0644 \\
(0.0801)\end{array}$ & $\begin{array}{l}19.9403 \\
(0.0682)\end{array}$ \\
\hline 2 & $\operatorname{VAR}(2)$ & $\begin{array}{c}9.3966 \\
(0.0519)\end{array}$ & $\begin{array}{l}13.1657 \\
(0.1063)\end{array}$ & $\begin{array}{l}18.0620 \\
(0.1138)\end{array}$ & $\begin{array}{c}0.6457 \\
(0.9579)\end{array}$ & $\begin{array}{c}7.0639 \\
(0.5298)\end{array}$ & $\begin{array}{l}11.9596 \\
(0.4489)\end{array}$ \\
\hline 3 & $\operatorname{VAR}(3)$ & $\begin{array}{c}1.1256 \\
(0.8902)\end{array}$ & $\begin{array}{c}5.7860 \\
(0.6712)\end{array}$ & $\begin{array}{l}13.0501 \\
(0.3654)\end{array}$ & $\begin{array}{c}0.4326 \\
(0.9797)\end{array}$ & $\begin{array}{c}6.9116 \\
(0.5462)\end{array}$ & $\begin{array}{l}11.4277 \\
(0.4927)\end{array}$ \\
\hline 4 & $\operatorname{VAR}(4)$ & $\begin{array}{c}2.0670 \\
(0.7234)\end{array}$ & $\begin{array}{c}8.1360 \\
(0.4203)\end{array}$ & $\begin{array}{c}16.3909 \\
(0.1740)\end{array}$ & $\begin{array}{c}1.0587 \\
(0.9008)\end{array}$ & $\begin{array}{c}7.9186 \\
(0.4415)\end{array}$ & $\begin{array}{c}12.5186 \\
(0.4050)\end{array}$ \\
\hline 5 & $\operatorname{VAR}(5)$ & $\begin{array}{c}2.6370 \\
(0.6203)\end{array}$ & $\begin{array}{c}5.9525 \\
(0.6525)\end{array}$ & $\begin{array}{l}14.3707 \\
(0.2777)\end{array}$ & $\begin{array}{c}3.4865 \\
(0.4799)\end{array}$ & $\begin{array}{c}7.8950 \\
(0.4438)\end{array}$ & $\begin{array}{l}12.2289 \\
(0.4275)\end{array}$ \\
\hline \multirow[t]{4}{*}{6} & $\operatorname{VAR}(6)$ & $\begin{array}{c}1.5217 \\
(0.8228) \\
\end{array}$ & $\begin{array}{c}5.3154 \\
(0.7234) \\
\end{array}$ & $\begin{array}{r}12.4706 \\
(0.4087) \\
\end{array}$ & $\begin{array}{c}5.4596 \\
(0.2433) \\
\end{array}$ & $\begin{array}{r}10.5558 \\
(0.2282) \\
\end{array}$ & $\begin{array}{l}15.3021 \\
(0.2253) \\
\end{array}$ \\
\hline & Equation & \multicolumn{6}{|c|}{ B.2. Squared standardised residuals of output equation } \\
\hline & Country & \multicolumn{3}{|c|}{ US } & \multicolumn{3}{|c|}{ UK } \\
\hline & Specification & $\mathrm{Q}(4)$ & $\mathrm{Q}(8)$ & $\mathrm{Q}(12)$ & $\mathrm{Q}(4)$ & $\mathrm{Q}(8)$ & $\mathrm{Q}(12)$ \\
\hline 1 & $\operatorname{VAR}(1)$ & $\begin{array}{c}2.4692 \\
(0.6502)\end{array}$ & $\begin{array}{c}6.6809 \\
(0.5714)\end{array}$ & $\begin{array}{c}9.8981 \\
(0.6249)\end{array}$ & $\begin{array}{c}1.0417 \\
(0.9034)\end{array}$ & $\begin{array}{c}6.2758 \\
(0.6164)\end{array}$ & $\begin{array}{l}13.4932 \\
(0.3342)\end{array}$ \\
\hline 2 & $\operatorname{VAR}(2)$ & $\begin{array}{c}2.4925 \\
(0.6460)\end{array}$ & $\begin{array}{c}7.6303 \\
(0.4704)\end{array}$ & $\begin{array}{c}9.6925 \\
(0.6429)\end{array}$ & $\begin{array}{c}2.0050 \\
(0.7348)\end{array}$ & $\begin{array}{c}7.2336 \\
(0.5116)\end{array}$ & $\begin{array}{l}15.0224 \\
(0.2402)\end{array}$ \\
\hline 3 & $\operatorname{VAR}(3)$ & $\begin{array}{c}2.1600 \\
(0.7064)\end{array}$ & $\begin{array}{c}6.2214 \\
(0.6224)\end{array}$ & $\begin{array}{c}7.9480 \\
(0.7892)\end{array}$ & $\begin{array}{c}1.6503 \\
(0.7997)\end{array}$ & $\begin{array}{c}6.2484 \\
(0.6194)\end{array}$ & $\begin{array}{l}10.0118 \\
(0.6149)\end{array}$ \\
\hline 4 & $\operatorname{VAR}(4)$ & $\begin{array}{c}1.4212 \\
(0.8405)\end{array}$ & $\begin{array}{c}4.6975 \\
(0.7894)\end{array}$ & $\begin{array}{c}6.0980 \\
(0.9111)\end{array}$ & $\begin{array}{c}1.3660 \\
(0.8501)\end{array}$ & $\begin{array}{c}6.1082 \\
(0.6351)\end{array}$ & $\begin{array}{c}9.9252 \\
(0.6225)\end{array}$ \\
\hline 5 & $\operatorname{VAR}(5)$ & $\begin{array}{c}1.3635 \\
(0.8505)\end{array}$ & $\begin{array}{c}4.3343 \\
(0.8258)\end{array}$ & $\begin{array}{c}5.7114 \\
(0.9300)\end{array}$ & $\begin{array}{c}1.2370 \\
(0.8720)\end{array}$ & $\begin{array}{c}5.4115 \\
(0.7128)\end{array}$ & $\begin{array}{c}8.7380 \\
(0.7251)\end{array}$ \\
\hline \multirow[t]{4}{*}{6} & VAR(6) & $\begin{array}{c}2.3861 \\
(0.6651) \\
\end{array}$ & $\begin{array}{r}5.5442 \\
(0.6981) \\
\end{array}$ & $\begin{array}{c}7.9061 \\
(0.7924) \\
\end{array}$ & $\begin{array}{r}1.8619 \\
(0.7611) \\
\end{array}$ & $\begin{array}{r}4.8349 \\
(0.7751) \\
\end{array}$ & $\begin{array}{r}7.9164 \\
(0.7916) \\
\end{array}$ \\
\hline & Equation & \multicolumn{6}{|c|}{ B.3. Stan } \\
\hline & Country & \multicolumn{3}{|c|}{ US } & \multicolumn{3}{|c|}{ UK } \\
\hline & Specification & $\mathrm{Q}(4)$ & $\mathrm{Q}(8)$ & $\mathrm{Q}(12)$ & $\mathrm{Q}(4)$ & $\mathrm{Q}(8)$ & $\mathrm{Q}(12)$ \\
\hline 1 & VAR(1) & $\begin{array}{l}18.2155 \\
(0.0011)\end{array}$ & $\begin{array}{l}57.0915 \\
(0.0000)\end{array}$ & $\begin{array}{l}118.6496 \\
(0.0000)\end{array}$ & $\begin{array}{c}9.2697 \\
(0.0547)\end{array}$ & $\begin{array}{l}72.9548 \\
(0.0000)\end{array}$ & $\begin{array}{c}280.2274 \\
(0.0000)\end{array}$ \\
\hline 2 & $\operatorname{VAR}(2)$ & $\begin{array}{c}7.5852 \\
(0.1080)\end{array}$ & $\begin{array}{l}22.4549 \\
(0.0041)\end{array}$ & $\begin{array}{l}67.0974 \\
(0.0000)\end{array}$ & $\begin{array}{c}1.7916 \\
(0.7740)\end{array}$ & $\begin{array}{c}65.7753 \\
(0.0000)\end{array}$ & $\begin{array}{c}281.7923 \\
(0.0000)\end{array}$ \\
\hline 3 & VAR(3) & $\begin{array}{l}15.5166 \\
(0.0037)\end{array}$ & $\begin{array}{l}21.3550 \\
(0.0063)\end{array}$ & $\begin{array}{l}63.9702 \\
(0.0000)\end{array}$ & $\begin{array}{c}2.3863 \\
(0.6651)\end{array}$ & $\begin{array}{l}64.3302 \\
(0.0000)\end{array}$ & $\begin{array}{c}272.5958 \\
(0.0000)\end{array}$ \\
\hline 4 & $\operatorname{VAR}(4)$ & $\begin{array}{l}15.7682 \\
(0.0033)\end{array}$ & $\begin{array}{l}19.8813 \\
(0.0108)\end{array}$ & $\begin{array}{l}57.2875 \\
(0.0000)\end{array}$ & $\begin{array}{c}1.9730 \\
(0.7407)\end{array}$ & $\begin{array}{l}57.4420 \\
(0.0000)\end{array}$ & $\begin{array}{r}259.3445 \\
(0.0000)\end{array}$ \\
\hline 5 & VAR(5) & $\begin{array}{l}10.3871 \\
(0.0344)\end{array}$ & $\begin{array}{l}23.4014 \\
(0.0029)\end{array}$ & $\begin{array}{l}55.4166 \\
(0.0000)\end{array}$ & $\begin{array}{c}6.6250 \\
(0.1571)\end{array}$ & $\begin{array}{l}52.8968 \\
(0.0000)\end{array}$ & $\begin{array}{c}259.5368 \\
(0.0000)\end{array}$ \\
\hline 6 & $\operatorname{VAR}(6)$ & $\begin{array}{r}10.3809 \\
(0.0345) \\
\end{array}$ & $\begin{array}{l}20.7760 \\
(0.0078) \\
\end{array}$ & $\begin{array}{l}52.0211 \\
(0.0000) \\
\end{array}$ & $\begin{array}{c}7.3814 \\
(0.1171) \\
\end{array}$ & $\begin{array}{l}10.1727 \\
(0.2531) \\
\end{array}$ & $\begin{array}{r}194.2168 \\
(0.0000) \\
\end{array}$ \\
\hline
\end{tabular}




\begin{tabular}{|c|c|c|c|c|c|c|c|}
\hline & Equation & \multicolumn{6}{|c|}{ B.4. Squared standardised residuals of inflation equation } \\
\hline & Country & \multicolumn{3}{|c|}{ US } & \multicolumn{3}{|c|}{ UK } \\
\hline & Specification & $\mathrm{Q}(4)$ & $\mathrm{Q}(8)$ & $\mathrm{Q}(12)$ & $\mathrm{Q}(4)$ & $\mathrm{Q}(8)$ & $\mathrm{Q}(12)$ \\
\hline 1 & $\operatorname{VAR}(1)$ & $\begin{array}{c}2.2887 \\
(0.6828)\end{array}$ & $\begin{array}{c}4.4329 \\
(0.8161)\end{array}$ & $\begin{array}{c}7.4680 \\
(0.8252)\end{array}$ & $\begin{array}{c}2.9195 \\
(0.5714)\end{array}$ & $\begin{array}{c}9.7373 \\
(0.2840)\end{array}$ & $\begin{array}{l}88.4653 \\
(0.0000)\end{array}$ \\
\hline 2 & $\operatorname{VAR}(2)$ & $\begin{array}{c}2.2505 \\
(0.6898)\end{array}$ & $\begin{array}{c}4.9169 \\
(0.7664)\end{array}$ & $\begin{array}{c}8.0459 \\
(0.7815)\end{array}$ & $\begin{array}{c}4.7997 \\
(0.3085)\end{array}$ & $\begin{array}{l}14.7044 \\
(0.0652)\end{array}$ & $\begin{array}{c}106.8069 \\
(0.0000)\end{array}$ \\
\hline 3 & $\operatorname{VAR}(3)$ & $\begin{array}{c}2.8944 \\
(0.5756)\end{array}$ & $\begin{array}{c}5.9978 \\
(0.6475)\end{array}$ & $\begin{array}{c}9.8793 \\
(0.6266)\end{array}$ & $\begin{array}{c}5.1172 \\
(0.2755)\end{array}$ & $\begin{array}{l}14.3995 \\
(0.0719)\end{array}$ & $\begin{array}{c}117.4897 \\
(0.0000)\end{array}$ \\
\hline 4 & $\operatorname{VAR}(4)$ & $\begin{array}{c}4.0984 \\
(0.3928)\end{array}$ & $\begin{array}{c}7.9958 \\
(0.4339)\end{array}$ & $\begin{array}{l}11.8321 \\
(0.4593)\end{array}$ & $\begin{array}{c}5.3068 \\
(0.2572)\end{array}$ & $\begin{array}{l}14.4552 \\
(0.0706)\end{array}$ & $\begin{array}{c}122.7932 \\
(0.0000)\end{array}$ \\
\hline 5 & $\operatorname{VAR}(5)$ & $\begin{array}{c}3.5264 \\
(0.4739)\end{array}$ & $\begin{array}{c}6.9134 \\
(0.5460)\end{array}$ & $\begin{array}{l}10.3361 \\
(0.5865)\end{array}$ & $\begin{array}{c}5.9338 \\
(0.2041)\end{array}$ & $\begin{array}{l}14.6910 \\
(0.0654)\end{array}$ & $\begin{array}{c}127.7325 \\
(0.0000)\end{array}$ \\
\hline \multirow[t]{4}{*}{6} & $\operatorname{VAR}(6)$ & $\begin{array}{c}2.4113 \\
(0.6606) \\
\end{array}$ & $\begin{array}{r}6.2260 \\
(0.6219) \\
\end{array}$ & $\begin{array}{r}8.6663 \\
(0.7311) \\
\end{array}$ & $\begin{array}{r}4.6229 \\
(0.3282) \\
\end{array}$ & $\begin{array}{l}10.8094 \\
(0.2127) \\
\end{array}$ & $\begin{array}{r}110.0863 \\
(0.0000) \\
\end{array}$ \\
\hline & Equation & \multicolumn{6}{|c|}{ B.5. Standardised residuals of equation for excess return } \\
\hline & Country & \multicolumn{3}{|c|}{ US } & \multicolumn{3}{|c|}{$\mathrm{UK}$} \\
\hline & Specification & $\mathrm{Q}(4)$ & $\mathrm{Q}(8)$ & $\mathrm{Q}(12)$ & $\mathrm{Q}(4)$ & $\mathrm{Q}(8)$ & $\mathrm{Q}(12)$ \\
\hline 1 & $\operatorname{VAR}(1)$ & $\begin{array}{l}42.3802 \\
(0.0000)\end{array}$ & $\begin{array}{l}54.0405 \\
(0.0000)\end{array}$ & $\begin{array}{l}56.6112 \\
(0.0000)\end{array}$ & $\begin{array}{c}7.1199 \\
(0.1297)\end{array}$ & $\begin{array}{c}8.8090 \\
(0.3587)\end{array}$ & $\begin{array}{c}13.8612 \\
(0.3097)\end{array}$ \\
\hline 2 & $\operatorname{VAR}(2)$ & $\begin{array}{l}42.6417 \\
(0.0000)\end{array}$ & $\begin{array}{l}54.3146 \\
(0.0000)\end{array}$ & $\begin{array}{l}56.9199 \\
(0.0000)\end{array}$ & $\begin{array}{c}7.0626 \\
(0.1326)\end{array}$ & $\begin{array}{c}8.8605 \\
(0.3542)\end{array}$ & $\begin{array}{l}14.1040 \\
(0.2941)\end{array}$ \\
\hline 3 & $\operatorname{VAR}(3)$ & $\begin{array}{l}42.6180 \\
(0.0000)\end{array}$ & $\begin{array}{l}54.0406 \\
(0.0000)\end{array}$ & $\begin{array}{l}56.4737 \\
(0.0000)\end{array}$ & $\begin{array}{c}6.5200 \\
(0.1635)\end{array}$ & $\begin{array}{c}8.9151 \\
(0.3495)\end{array}$ & $\begin{array}{l}14.1870 \\
(0.2889)\end{array}$ \\
\hline 4 & $\operatorname{VAR}(4)$ & $\begin{array}{l}39.2884 \\
(0.0000)\end{array}$ & $\begin{array}{l}50.8551 \\
(0.0000)\end{array}$ & $\begin{array}{l}54.0871 \\
(0.0000)\end{array}$ & $\begin{array}{c}6.5568 \\
(0.1612)\end{array}$ & $\begin{array}{c}8.9347 \\
(0.3478)\end{array}$ & $\begin{array}{l}14.0927 \\
(0.2948)\end{array}$ \\
\hline 5 & $\operatorname{VAR}(5)$ & $\begin{array}{l}41.1572 \\
(0.0000)\end{array}$ & $\begin{array}{l}52.5583 \\
(0.0000)\end{array}$ & $\begin{array}{l}55.7301 \\
(0.0000)\end{array}$ & $\begin{array}{c}6.4924 \\
(0.1653)\end{array}$ & $\begin{array}{c}8.7189 \\
(0.3666)\end{array}$ & $\begin{array}{l}13.6653 \\
(0.3226)\end{array}$ \\
\hline \multirow[t]{4}{*}{6} & $\operatorname{VAR}(6)$ & $\begin{array}{l}39.1574 \\
(0.0000) \\
\end{array}$ & $\begin{array}{r}50.1230 \\
(0.0000) \\
\end{array}$ & $\begin{array}{l}53.1864 \\
(0.0000) \\
\end{array}$ & $\begin{array}{c}5.9891 \\
(0.2000) \\
\end{array}$ & $\begin{array}{c}8.8702 \\
(0.3534) \\
\end{array}$ & $\begin{array}{r}13.3513 \\
(0.3440) \\
\end{array}$ \\
\hline & Equation & \multicolumn{6}{|c|}{ B.6. Squared standardised residuals of equation for excess return } \\
\hline & Country & & US & & & UK & \\
\hline & Specification & $\mathrm{Q}(4)$ & $\mathrm{Q}(8)$ & $\mathrm{Q}(12)$ & $\mathrm{Q}(4)$ & $\mathrm{Q}(8)$ & $\mathrm{Q}(12)$ \\
\hline 1 & VAR(1) & $\begin{array}{l}42.3802 \\
(0.0000)\end{array}$ & $\begin{array}{l}54.0405 \\
(0.0000)\end{array}$ & $\begin{array}{l}56.6112 \\
(0.0000)\end{array}$ & $\begin{array}{c}7.1199 \\
(0.1297)\end{array}$ & $\begin{array}{c}8.8090 \\
(0.3587)\end{array}$ & $\begin{array}{l}13.8612 \\
(0.3097)\end{array}$ \\
\hline 2 & $\operatorname{VAR}(2)$ & $\begin{array}{l}42.6417 \\
(0.0000)\end{array}$ & $\begin{array}{l}54.3146 \\
(0.0000)\end{array}$ & $\begin{array}{l}56.9199 \\
(0.0000)\end{array}$ & $\begin{array}{c}7.0626 \\
(0.1326)\end{array}$ & $\begin{array}{c}8.8605 \\
(0.3542)\end{array}$ & $\begin{array}{l}14.1040 \\
(0.2941)\end{array}$ \\
\hline 3 & $\operatorname{VAR}(3)$ & $\begin{array}{l}42.6180 \\
(0.0000)\end{array}$ & $\begin{array}{l}54.0406 \\
(0.0000)\end{array}$ & $\begin{array}{l}56.4737 \\
(0.0000)\end{array}$ & $\begin{array}{c}6.5200 \\
(0.1635)\end{array}$ & $\begin{array}{c}8.9151 \\
(0.3495)\end{array}$ & $\begin{array}{l}14.1870 \\
(0.2889)\end{array}$ \\
\hline 4 & $\operatorname{VAR}(4)$ & $\begin{array}{l}39.2884 \\
(0.0000)\end{array}$ & $\begin{array}{l}50.8551 \\
(0.0000)\end{array}$ & $\begin{array}{l}54.0871 \\
(0.0000)\end{array}$ & $\begin{array}{c}6.5568 \\
(0.1612)\end{array}$ & $\begin{array}{c}8.9347 \\
(0.3478)\end{array}$ & $\begin{array}{l}14.0927 \\
(0.2948)\end{array}$ \\
\hline 5 & $\operatorname{VAR}(5)$ & $\begin{array}{l}41.1572 \\
(0.0000)\end{array}$ & $\begin{array}{l}52.5583 \\
(0.0000)\end{array}$ & $\begin{array}{l}55.7301 \\
(0.0000)\end{array}$ & $\begin{array}{c}6.4924 \\
(0.1653)\end{array}$ & $\begin{array}{c}8.7189 \\
(0.3666)\end{array}$ & $\begin{array}{l}13.6653 \\
(0.3226)\end{array}$ \\
\hline 6 & $\operatorname{VAR}(6)$ & $\begin{array}{l}39.1574 \\
(0.0000)\end{array}$ & $\begin{array}{l}50.1230 \\
(0.0000)\end{array}$ & $\begin{array}{l}53.1864 \\
(0.0000)\end{array}$ & $\begin{array}{c}5.9891 \\
(0.2000) \\
\end{array}$ & $\begin{array}{c}8.8702 \\
(0.3534) \\
\end{array}$ & $\begin{array}{l}13.3513 \\
(0.3440)\end{array}$ \\
\hline
\end{tabular}


Table 3 - Model 1

\section{Panel A - Estimation}

In his table, we report estimates of the modified EGARCH-M (corresponding p-values in brackets). Models for the UK conditional volatility are estimated using sample 1964:1 - 2004:12. Models for the US conditional volatility are estimated using sample 1950:1 - 2004:12. The triangular decomposition of the variance and covariance matrix is performed in order to identify structural innovations. Output growth is ordered first, inflation is ordered second, and excess return third. The Schwarz Bayesian Information Criterion (BIC) is used to determine the optimal lag length for the restricted vector autoregressions (VARs) in the conditional mean equation (see Panel A). VAR(1) and VAR(3) are selected and fitted for the UK and the US, respectively. The conditional variance model uses the long-term government yield as exogenous explanatory variable. In rows 1-13 we report estimates of the conditional mean model. Row 14 depict average monthly risk premium (in percentage terms). In rows 15-19 we report estimates of the conditional variance model. In rows 20-22 we report estimates of the off-diagonal element $q_{i j}$ of the Cholesky factor matrix (lower triangular matrix) and the implied correlations (upper triangular matrix) with the corresponding asymptotic p-values in brackets. Row 23 shows the log-likelihood value that is obtained upon MLE estimation. Bollerslev and Wooldridge (1992) robust quasi-maximum likelihood (QML) estimation of variance and covariance matrix of parameter estimates is calculated.

\begin{tabular}{|c|c|c|c|c|c|c|c|}
\hline \multirow{4}{*}{$\bar{r}$} & \multirow{3}{*}{$\begin{array}{c}\text { Country } \\
\text { Variable }\end{array}$} & \multicolumn{3}{|c|}{ US } & \multicolumn{3}{|c|}{ UK } \\
\hline & & IP & CPI & Excess & IP & $\mathrm{CPI}$ & Excess \\
\hline & & Growth & Inflation & Return & Growth & Inflation & Return \\
\hline & & \multicolumn{6}{|c|}{ Conditional mean } \\
\hline \multirow[t]{2}{*}{1} & const & 0.1186 & 0.0740 & & 0.2111 & 0.2721 & \\
\hline & & $(0.0104)$ & $(0.0000)$ & & $(0.0000)$ & $(0.0000)$ & \\
\hline \multirow[t]{2}{*}{2} & $\Delta \mathrm{y}_{\mathrm{t}-1}$ & 0.2290 & -0.0049 & & -0.1599 & -0.0021 & \\
\hline & & $(0.0000)$ & $(0.5655)$ & & $(0.0001)$ & $(0.8789)$ & \\
\hline \multirow[t]{2}{*}{3} & $\Delta \mathrm{y}_{\mathrm{t}-2}$ & 0.1223 & -0.0014 & & & & \\
\hline & & $(0.0067)$ & $(0.8801)$ & & & & \\
\hline \multirow[t]{2}{*}{4} & $\Delta \mathrm{y}_{\mathrm{t}-3}$ & 0.1321 & 0.0060 & & & & \\
\hline & & $(0.0006)$ & $(0.4851)$ & & & & \\
\hline \multirow[t]{2}{*}{5} & $\pi_{\mathrm{t}-1}$ & 0.0634 & 0.4044 & & -0.1374 & 0.4075 & \\
\hline & & $(0.6094)$ & $(0.0000)$ & & $(0.0265)$ & $(0.0000)$ & \\
\hline \multirow[t]{2}{*}{6} & $\pi_{t-2}$ & -0.2159 & 0.1705 & & & & \\
\hline & & $(0.0757)$ & $(0.0006)$ & & & & \\
\hline \multirow[t]{2}{*}{7} & $\pi_{t-3}$ & 0.0183 & 0.1712 & & & & \\
\hline & & $(0.8886)$ & $(0.0001)$ & & & & \\
\hline \multirow[t]{2}{*}{8} & $r_{t-1}^{e}$ & 0.0070 & 0.0010 & & 0.0064 & 0.0013 & \\
\hline & & $(0.2220)$ & $(0.6910)$ & & $(0.4379)$ & $(0.0023)$ & \\
\hline \multirow[t]{2}{*}{9} & $\mathrm{r}_{\mathrm{t}-2}^{\mathrm{e}}$ & 0.0225 & 0.0009 & & & & \\
\hline & & $(0.0039)$ & $(0.7156)$ & & & & \\
\hline \multirow[t]{2}{*}{10} & $r_{t-3}^{e}$ & 0.0233 & -0.0023 & & & & \\
\hline & & $(0.0041)$ & $(0.3552)$ & & & & \\
\hline \multirow[t]{2}{*}{11} & $\operatorname{Var}_{t-1}\left(r_{t}\right)$ & & & -0.0121 & & & -0.0082 \\
\hline & & & & $(0.4929)$ & & & $(0.4481)$ \\
\hline \multirow[t]{2}{*}{12} & $\operatorname{Cov}_{\mathrm{t}-1}\left(\mathrm{r}_{\mathrm{t}}, \Delta \mathrm{y}_{\mathrm{t}}\right)$ & & & 13.6206 & & & -9.8692 \\
\hline & & & & $(0.7896)$ & & & $(0.4817)$ \\
\hline \multirow[t]{2}{*}{13} & $\operatorname{Cov}_{\mathrm{t}-1}\left(\mathrm{r}_{\mathrm{t}}, \pi_{\mathrm{t}}\right)$ & & & -5.5952 & & & 1.7252 \\
\hline & & & & $(0.1332)$ & & & $(0.0000)$ \\
\hline \multirow[t]{3}{*}{14} & Risk Premium & & & 0.7166 & & & 0.6450 \\
\hline & (Monthly \%) & & & & & & \\
\hline & & \multicolumn{6}{|c|}{ Conditional variance } \\
\hline \multirow[t]{2}{*}{15} & Const & 0.0336 & -0.2751 & 0.4996 & -1.3630 & -4.3569 & 0.6560 \\
\hline & & $(0.1309)$ & $(0.0000)$ & $(0.0003)$ & $(0.0000)$ & $(0.0000)$ & $(0.0000)$ \\
\hline \multirow[t]{2}{*}{16} & GARCH & 0.9178 & 0.9125 & 0.7523 & 0.2414 & -0.5573 & 0.6497 \\
\hline & & $(0.0000)$ & $(0.0000)$ & $(0.0000)$ & $(0.0076)$ & $(0.0000)$ & $(0.0000)$ \\
\hline 17 & Sign ARCH & -0.2192 & 0.0186 & -0.1992 & 0.0037 & -0.0290 & -0.1579 \\
\hline
\end{tabular}




\begin{tabular}{cccccccc} 
& & $(0.0000)$ & $(0.5967)$ & $(0.0000)$ & $(0.9548)$ & $(0.5481)$ & $(0.0006)$ \\
18 & Size ARCH & 0.2621 & 0.2688 & 0.2347 & 0.8529 & 0.5439 & 0.2331 \\
& & $(0.0000)$ & $(0.0000)$ & $(0.0001)$ & $(0.0000)$ & $(0.0000)$ & $(0.0090)$ \\
19 & Long Rate & -0.1291 & 0.0192 & 0.1664 & 2.0937 & 3.0906 & 0.6570 \\
& & $(0.0030)$ & $(0.6566)$ & $(0.0579)$ & $(0.0000)$ & $(0.0000)$ & $(0.0039)$ \\
\hline & & \multicolumn{7}{c}{ Conditional correlations } \\
\hline 20 & Chol Factor 1】 & 1 & 0.0239 & 0.0102 & 1 & 0.0747 & -0.0033 \\
& Implied Corr & & $(0.0203)$ & $(0.0266)$ & & $(0.0181)$ & $(0.0184)$ \\
& & & & & & \\
21 & Chol Factor 2 \} $&{0.0066} &{1} &{-0.0674} &{0.0320} &{1} &{0.0662} \\
{ } &{\text { Implied Corr }} &{(0.5350)} &{ } &{(0.0411)} &{(0.0000)} &{ } &{(0.0003)} \\
{22} &{\text { Chol Factor 3\} } &{0.0425} &{-0.9852} &{1} &{-0.0142} &{0.6387} &{1} \\
{ } &{\text { Implied Corr }} &{(0.7839)} &{(0.0654)} &{ } &{(0.5030)} &{(0.0001)} &{ } \\
{\hline 23} &{\text { LogL }} &{ } &{-527.1957} &{ } &{ } &{-1265.2810} &{ } \\
{\hline}\end{array}$
\end{tabular}

\section{Panel B - Engle and Ng (1993) Tests}

This panel presents diagnostics for the estimates of the modified EGARCH-M models. In Panel A, we report the pvalues of Sign bias, Negative size bias, Positive size bias, and Joint tests proposed by Engle and Ng (1993). They proposed a series of tests in order to examine predictability of the squared normalised residuals by using some variables observed in the past that, however, are omitted from the volatility model being studied. Because empirical evidence shows that a large negative shock has a different impact on volatility than a positive shock of the same magnitude, the negative and positive shocks have to be distinguished between in terms of magnitude effects. The Sign bias test underlies the following auxiliary regression:

$$
z_{i, t}^{2}=\delta_{i, 0}+\delta_{i, 1} I\left(\hat{u}_{i, t-1}<0\right)+\omega_{i, t} .
$$

It examines the impact of negative and positive unexpected news not predicted by the volatility model being considered. If the volatility model is correctly specified, we would expect series $z_{i, t}^{2}$ to be unpredictable, that is, $\delta_{i, 1}$ shouldn't be statistically different from zero. The test is based on the t-Statistic of the null hypothesis $\delta_{i, 1}=0$. The Negative size bias test features the following specification:

$$
z_{i, t}^{2}=\delta_{i, 0}+\delta_{i, 1} \hat{u}_{i, t-1} I\left(\hat{u}_{i, t-1}<0\right)+\omega_{i, t} .
$$

The tests focuses on the differential effect between large and small negative unexpected news on volatility not predicted by the volatility being considered. If the volatility model is correctly specified, we would expect series $z_{i, t}^{2}$ to be unpredictable, that is, $\delta_{i, 1}$ shouldn't be statistically different from zero. The test is based on the t-Statistic of the null hypothesis $\delta_{i, 1}=0$. The Positive size bias test features the following auxiliary regression:

$$
z_{i, t}^{2}=\delta_{i, 0}+\delta_{i, 1} \hat{u}_{i, t-1} I\left(\hat{u}_{i, t-1}>0\right)+\omega_{i, t} .
$$

The Positive size bias test considers the differential effect that large and small positive shocks may have on volatility, which is not explained by the volatility model being considered. The test is based on the t-Statistic of the null hypothesis $\delta_{i, 1}=0$. The Joint test comprises the auxiliary regression

$$
z_{i, t}^{2}=\delta_{i, 0}+\delta_{i, 1} I\left(\hat{u}_{i, t-1}<0\right)+\delta_{i, 2} \hat{u}_{i, t-1} I\left(\hat{u}_{i, t-1}<0\right)+\delta_{i, 3} \hat{u}_{i, t-1} I\left(\hat{u}_{i, t-1}>0\right)+\omega_{i, t} .
$$

The Joint test is based on $\chi^{2}$-Statistic of the null hypothesis that parameters $\delta_{i, 1}, \delta_{i, 2}$, and $\delta_{i, 2}$ are jointly zero.

In Panel B, we report the p-values of Sign bias, Negative size bias, Positive size bias, and Joint tests proposed by Engle and $\mathrm{Ng}$ (1993). 


\begin{tabular}{cccccccc}
\hline \hline & Country & \multicolumn{1}{c}{ US } & & UK & \\
\hline & Engle and & IP & CPI & Excess & IP & RPI & Excess \\
& Ng Test & Growth & Inflation & Return & Growth & Inflation & Return \\
\hline 1 & Neg. Sign & 0.7473 & 0.8745 & 0.4625 & 0.8335 & 0.5712 & 0.9384 \\
2 & Neg. Size & 0.0620 & 0.3174 & 0.3735 & 0.8153 & 0.3089 & 0.2623 \\
3 & Pos. Size & 0.4445 & 0.9412 & 0.5349 & 0.9241 & 0.8081 & 0.8342 \\
4 & Joint & 0.1585 & 0.5532 & 0.1166 & 0.9837 & 0.2295 & 0.5832 \\
\hline
\end{tabular}

\section{Panel C - Nelson (1991) Tests}

In Panel C, we report the p-values of Nelson (1991) tests for orthogonality conditions of standardised residuals. In rows 14, we report the p-values of Nelson tests for orthogonality conditions for the first four moments of standardised residuals. In rows 59, we report the p-values of Nelson tests for orthogonality conditions for autocorrelation of squared standardised residuals up to order 5. In rows 10-14, we report the p-values of Nelson tests for orthogonality conditions for autocorrelation of standardised residuals up to order 5.

\begin{tabular}{cccccccc}
\hline \hline & Country & \multicolumn{3}{c}{ US } & UK & \\
\hline & Orthogonality condition & $\begin{array}{c}\text { IP } \\
\text { Growth }\end{array}$ & $\begin{array}{c}\text { CPI } \\
\text { Inflation }\end{array}$ & $\begin{array}{c}\text { Excess } \\
\text { Return }\end{array}$ & $\begin{array}{c}\text { IP } \\
\text { Growth }\end{array}$ & $\begin{array}{c}\text { CPI } \\
\text { Inflation }\end{array}$ & $\begin{array}{c}\text { Excess } \\
\text { Return }\end{array}$ \\
\hline 1 & $E\left(z_{i, t}\right)=0$ & 0.4567 & 0.6616 & 0.0000 & 0.8061 & 0.7383 & 0.8585 \\
2 & $E\left(z_{i, t}^{2}-1\right)=0$ & 0.9092 & 0.9812 & 0.4445 & 0.9999 & 0.9877 & 0.9848 \\
3 & $E\left(z_{i, t}^{3}\right)=0$ & 0.9815 & 0.3029 & 0.4665 & 0.2375 & 0.0086 & 0.0881 \\
4 & $E\left(z_{i, t}^{4}-3\right)=0$ & 0.0574 & 0.2052 & 0.1752 & 0.2078 & 0.1180 & 0.2527 \\
5 & $E\left[\left(z_{i, t}^{2}-1\right)\left(z_{i, t-1}^{2}-1\right)\right]=0$ & 0.1307 & 0.3865 & 0.6868 & 0.6157 & 0.5184 & 0.1785 \\
6 & $E\left[\left(z_{i, t}^{2}-1\right)\left(z_{i, t-2}^{2}-1\right)\right]=0$ & 0.7956 & 0.3337 & 0.6106 & 0.4839 & 0.0881 & 0.2378 \\
7 & $E\left[\left(z_{i, t}^{2}-1\right)\left(z_{i, t-3}^{2}-1\right)\right]=0$ & 0.6724 & 0.9484 & 0.5308 & 0.8517 & 0.3862 & 0.7985 \\
8 & $E\left[\left(z_{i, t}^{2}-1\right)\left(z_{i, t-4}^{2}-1\right)\right]=0$ & 0.6495 & 0.2068 & 0.6476 & 0.7863 & 0.0556 & 0.8556 \\
9 & $E\left[\left(z_{i, t}^{2}-1\right)\left(z_{i, t-5}^{2}-1\right)\right]=0$ & 0.9248 & 0.8979 & 0.0604 & 0.5949 & 0.0052 & 0.7580 \\
10 & $E\left(z_{i, t} z_{i t-1}\right)=0$ & 0.8453 & 0.9761 & 0.0000 & 0.5531 & 0.1278 & 0.1220 \\
11 & $E\left(z_{i, t} z_{t-2}\right)=0$ & 0.4510 & 0.2292 & 0.0167 & 0.0299 & 0.0195 & 0.1774 \\
12 & $E\left(z_{i, t} z_{t-3}\right)=0$ & 0.5711 & 0.0002 & 0.0145 & 0.2598 & 0.9002 & 0.3919 \\
13 & $E\left(z_{i, t} z_{t-4}\right)=0$ & 0.6994 & 0.5882 & 0.0066 & 0.7281 & 0.0785 & 0.1311 \\
14 & $E\left(z_{i, t} z_{t-5}\right)=0$ & 0.0494 & 0.2579 & 0.0002 & 0.0778 & 0.0886 & 0.3966 \\
\hline \hline
\end{tabular}


Table 4 - Model 2

\section{Panel A - Estimation}

In his table, we report estimates of the modified EGARCH-M models (corresponding asymptotic p-values in brackets). Models for the UK conditional volatility are estimated using sample 1964:1 - 2004:12. Models for the US conditional volatility are estimated using sample 1950:1 - 2004:12. The triangular decomposition of the variance and covariance matrix is performed in order to identify structural innovations. Output growth is ordered first, inflation is ordered second, and excess return third. The conditional variance model uses the long-term government yields and short-term interest rates as exogenous explanatory variables. In rows 1-13 we report estimates of the conditional mean model. Row 14 depicts average monthly risk premium (in percentage terms). In rows 15-20 we report estimates of the conditional variance model. In rows 20-22 we report estimates of the off-diagonal element $q_{i j}$ of the Cholesky factor matrix (lower triangular matrix) and the implied correlations (upper triangular matrix) with the corresponding asymptotic p-values in brackets. Row 24 shows the log-likelihood value that is obtained upon MLE estimation. Bollerslev and Wooldridge (1992) robust quasi-maximum likelihood (QML) estimation of variance and covariance matrix of parameter estimates is calculated.

\begin{tabular}{|c|c|c|c|c|c|c|c|}
\hline \multirow{3}{*}{\multicolumn{2}{|c|}{$\begin{array}{c}\text { Country } \\
\text { Variable }\end{array}$}} & \multicolumn{3}{|c|}{ US } & \multicolumn{3}{|c|}{ UK } \\
\hline & & IP & CPI & Excess & IP & RPI & Excess \\
\hline & & Growth & Inflation & Return & Growth & Inflation & Return \\
\hline & & \multicolumn{6}{|c|}{ Conditional mean } \\
\hline \multirow[t]{2}{*}{1} & const & 0.1594 & 0.0722 & & 0.2113 & 0.2686 & \\
\hline & & $(0.0036)$ & $(0.0000)$ & & $(0.0000)$ & $(0.0000)$ & \\
\hline \multirow[t]{2}{*}{2} & $\Delta \mathrm{y}_{\mathrm{t}-1}$ & 0.2210 & -0.0046 & & -0.1637 & 0.0032 & \\
\hline & & $(0.0000)$ & $(0.6009)$ & & $(0.0007)$ & $(0.8452)$ & \\
\hline \multirow[t]{2}{*}{3} & $\Delta \mathrm{y}_{\mathrm{t}-2}$ & 0.1207 & -0.0027 & & & & \\
\hline & & $(0.0063)$ & $(0.7910)$ & & & & \\
\hline \multirow[t]{2}{*}{4} & $\Delta \mathrm{y}_{\mathrm{t}-3}$ & 0.1214 & 0.0067 & & & & \\
\hline & & $(0.0023)$ & $(0.4598)$ & & & & \\
\hline \multirow[t]{2}{*}{5} & $\pi_{\mathrm{t}-1}$ & 0.0573 & 0.4028 & & -0.1320 & 0.4100 & \\
\hline & & $(0.6632)$ & $(0.0000)$ & & $(0.0719)$ & $(0.0000)$ & \\
\hline \multirow[t]{2}{*}{6} & $\pi_{t-2}$ & -0.2246 & 0.1703 & & & & \\
\hline & & $(0.0987)$ & $(0.0008)$ & & & & \\
\hline \multirow[t]{2}{*}{7} & $\pi_{t-3}$ & -0.0158 & 0.1746 & & & & \\
\hline & & $(0.9106)$ & $(0.0001)$ & & & & \\
\hline \multirow[t]{2}{*}{8} & $\mathrm{r}_{\mathrm{t}-1}^{\mathrm{e}}$ & 0.0079 & 0.0011 & & 0.0068 & 0.0021 & \\
\hline & & $(0.2302)$ & $(0.6802)$ & & $(0.4084)$ & $(0.5099)$ & \\
\hline \multirow[t]{2}{*}{9} & $r_{t-2}^{e}$ & 0.0190 & 0.0010 & & & & \\
\hline & & $(0.0185)$ & $(0.7047)$ & & & & \\
\hline \multirow[t]{2}{*}{10} & $r_{t-3}^{e}$ & 0.0215 & -0.0023 & & & & \\
\hline & & $(0.0113)$ & $(0.3725)$ & & & & \\
\hline \multirow[t]{2}{*}{11} & $\operatorname{Var}_{t-1}\left(r_{t}\right)$ & & & -0.0218 & & & -0.0036 \\
\hline & & & & $(0.2651)$ & & & $(0.8130)$ \\
\hline \multirow[t]{2}{*}{12} & $\operatorname{Cov}_{\mathrm{t}-1}\left(\mathrm{r}_{\mathrm{t}}, \Delta \mathrm{y}_{\mathrm{t}}\right)$ & & & 21.0094 & & & -4.9865 \\
\hline & & & & $(0.8357)$ & & & $(0.0192)$ \\
\hline \multirow[t]{2}{*}{13} & $\operatorname{Cov}_{t-1}\left(r_{t}, \pi_{t}\right)$ & & & -6.4730 & & & 1.1025 \\
\hline & & & & $(0.1529)$ & & & $(0.5557)$ \\
\hline \multirow[t]{3}{*}{14} & Risk Premium & & & 0.8361 & & & 0.5024 \\
\hline & (Monthly \%) & & & & & & \\
\hline & & \multicolumn{6}{|c|}{ Conditional variance } \\
\hline \multirow[t]{2}{*}{15} & Const & 0.0442 & -0.2809 & 0.5782 & -1.3435 & -4.4906 & 0.6681 \\
\hline & & $(0.0360)$ & $(0.0000)$ & $(0.0002)$ & $(0.0001)$ & $(0.0000)$ & $(0.0002)$ \\
\hline \multirow[t]{2}{*}{16} & GARCH & 0.9180 & 0.9050 & 0.7523 & 0.2476 & -0.5552 & 0.6404 \\
\hline & & $(0.0000)$ & $(0.0000)$ & $(0.0000)$ & $(0.0338)$ & $(0.0000)$ & $(0.0029)$ \\
\hline \multirow[t]{2}{*}{17} & Sign ARCH & -0.1956 & 0.0042 & -0.1987 & 0.0068 & -0.0216 & -0.1556 \\
\hline & & $(0.0000)$ & $(0.9005)$ & $(0.0000)$ & $(0.9298)$ & $(0.6683)$ & $(0.0183)$ \\
\hline 18 & Size ARCH & 0.2196 & 0.2580 & 0.2297 & 0.8641 & 0.5372 & 0.2375 \\
\hline
\end{tabular}




\begin{tabular}{|c|c|c|c|c|c|c|c|}
\hline & & $(0.0000)$ & $(0.0000)$ & $(0.0001)$ & $(0.0000)$ & $(0.0000)$ & $(0.0423)$ \\
\hline 19 & Long Rate & -0.3968 & -0.1802 & -0.3498 & 1.7989 & 2.1567 & 0.6328 \\
\hline 20 & Short Rate & $\begin{array}{c}(0.0001) \\
03070\end{array}$ & $\begin{array}{c}(0.0979) \\
02179\end{array}$ & $\begin{array}{c}(0.0722) \\
0.5662\end{array}$ & $\begin{array}{c}(0.0032) \\
02915\end{array}$ & $\begin{array}{c}(0.0025) \\
12012\end{array}$ & $\begin{array}{c}(0.0003) \\
0.0543\end{array}$ \\
\hline 20 & Short Rate & $\begin{array}{l}0.30 / 0 \\
(0.0017)\end{array}$ & $(0.2179$ & $\begin{array}{r}0.5002 \\
(00071)\end{array}$ & $\begin{array}{r}0.2915 \\
(0.5063)\end{array}$ & 1.2012 & $(07071)$ \\
\hline & & \multicolumn{6}{|c|}{ Conditional correlations } \\
\hline \multirow{2}{*}{21} & Chol Factor 1। & 1 & 0.0267 & 0.0080 & 1 & 0.0 & -00063 \\
\hline & Implied Corr & & $(0.0118)$ & $(0.0186)$ & & $(0.0175)$ & $(0.0154)$ \\
\hline \multirow[t]{2}{*}{22} & Chol Factor 2\} $&{0.0075} &{1} &{-0.0658} &{0.0345} &{1} &{0.0655} \\
{\hline} &{\text { Implied Corr }} &{(0.4991)} &{ } &{(0.0016)} &{(0.0108)} &{ } &{(0.0003)} \\
{\hline \multirow[t]{2}{*}{23}2 3} &{\text { Chol Factor } 3 \backslash} &{0.0338} &{-0.9608} &{1} &{-0.0271} &{0.6381} &{1} \\
{\hline} &{\text { Implied Corr }} &{(0.8326)} &{(0.0691)} &{ } &{(0.2888)} &{(0.1133)} &{ } \\
{\hline 24} &{\log L} &{ } &{-515.6222} &{ } &{ } &{-1263.1825} &{ } \\
$\hline
\end{tabular}

Table 5 - Model 3

\section{Panel A - Estimation}

In his table, we report estimates of the modified EGARCH-M (corresponding p-values in brackets). Models for the UK conditional volatility are estimated using sample 1964:1 - 2004:12. Models for the US conditional volatility are estimated using sample 1950:1 - 2004:12. The triangular decomposition of the variance and covariance matrix is performed in order to identify structural innovations. Output growth is ordered first, inflation is ordered second, and excess return third. The conditional variance model uses the term spread as exogenous explanatory variable. In rows 1-13 we report estimates of the conditional mean model. Row 14 depicts average monthly risk premium (in percentage terms). In rows 15-19 we report estimates of the conditional variance model. In rows 20-22 we report estimates of the off-diagonal element $q_{i j}$ of the Cholesky factor matrix (lower triangular matrix) and the implied correlations (upper triangular matrix). Row 23 shows the log-likelihood value that is obtained upon MLE estimation. Bollerslev and Wooldridge (1992) robust quasi-maximum likelihood (QML) estimation of variance and covariance matrix of parameter estimates is calculated.

\begin{tabular}{|c|c|c|c|c|c|c|c|}
\hline \multirow{4}{*}{ 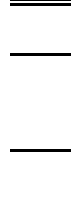 } & \multirow{3}{*}{$\begin{array}{l}\text { Country } \\
\text { Variable }\end{array}$} & \multicolumn{3}{|c|}{ US } & \multicolumn{3}{|c|}{ UK } \\
\hline & & IP & CPI & Excess & IP & RPI & Excess \\
\hline & & Growth & Inflation & Return & Growth & Inflation & Return \\
\hline & & \multicolumn{6}{|c|}{ Conditional mean } \\
\hline 1 & const & 0.1645 & 0.0757 & & 0.1888 & 0.2846 & \\
\hline & & $(0.0014)$ & $(0.0000)$ & & $(0.0023)$ & $(0.0000)$ & \\
\hline 2 & $\Delta \mathrm{y}_{\mathrm{t}-1}$ & 0.2060 & -0.0055 & & -0.1681 & 0.0208 & \\
\hline & & $(0.0000)$ & $(0.5317)$ & & $(0.0075)$ & & \\
\hline 3 & $\Delta \mathrm{y}_{\mathrm{t}-2}$ & 0.1439 & -0.0033 & & & & \\
\hline & & $(0.0019)$ & $(0.7353)$ & & & & \\
\hline 4 & $\Delta \mathrm{y}_{\mathrm{t}-3}$ & $\begin{array}{c}0.1473 \\
(0.0001)\end{array}$ & $\begin{array}{c}0.0076 \\
(0.3928)\end{array}$ & & & & \\
\hline 5 & $\pi_{t-1}$ & -0.0102 & 0.4039 & & -0.1240 & 0.4964 & \\
\hline & & $(0.9384)$ & $(0.0000)$ & & $(0.0983)$ & $(0.0000)$ & \\
\hline 6 & $\pi_{-2}$ & -0.2403 & 0.1637 & & & & \\
\hline & & $(0.0579)$ & $(0.0010)$ & & & & \\
\hline 7 & $\pi_{\mathrm{t}-3}$ & $\begin{array}{c}-0.0129 \\
(0.9205)\end{array}$ & $\begin{array}{c}0.1718 \\
(0.0001)\end{array}$ & & & & \\
\hline 8 & $r_{t-1}^{e}$ & 0.0083 & 0.0015 & & -0.0059 & 0.0075 & \\
\hline & & $(0.2315)$ & $(0.5689)$ & & $(0.3776)$ & $(0.0000)$ & \\
\hline 9 & $r_{t-2}^{e}$ & 0.0193 & 0.0008 & & & & \\
\hline & & $(0.0127)$ & $(0.7578)$ & & & & \\
\hline 10 & $r_{t-3}^{e}$ & $\begin{array}{c}0.0256 \\
(0.0019)\end{array}$ & $\begin{array}{c}-0.0017 \\
(0.5031)\end{array}$ & & & & \\
\hline
\end{tabular}




\begin{tabular}{|c|c|c|c|c|c|c|c|}
\hline 11 & $\operatorname{Var}_{t-1}\left(r_{t}\right)$ & \multicolumn{5}{|c|}{$\begin{array}{c}0.3313 \\
(0.2651)\end{array}$} & $\begin{array}{c}0.0136 \\
(0.2527)\end{array}$ \\
\hline 12 & $\operatorname{Cov}_{\mathrm{t}-1}\left(\mathrm{r}_{\mathrm{t}}, \Delta \mathrm{y}_{\mathrm{t}}\right)$ & \multicolumn{5}{|c|}{$\begin{array}{c}8.3553 \\
(0.9346)\end{array}$} & $\begin{array}{c}-0.5494 \\
(0.6570)\end{array}$ \\
\hline 13 & $\operatorname{Cov}_{\mathrm{t}-1}\left(\mathrm{r}_{\mathrm{t}}, \pi_{\mathrm{t}}\right)$ & \multicolumn{5}{|c|}{$\begin{array}{l}-3.6568 \\
(0.0531) \\
\end{array}$} & $\begin{array}{r}0.2197 \\
(0.8272) \\
\end{array}$ \\
\hline 14 & $\begin{array}{l}\text { Risk Premium } \\
\text { (Monthly \%) }\end{array}$ & \multicolumn{5}{|c|}{0.3729} & 0.1995 \\
\hline & & \multicolumn{6}{|c|}{ Conditional variance } \\
\hline 15 & Const & $\begin{array}{c}0.0097 \\
(0.5645)\end{array}$ & $\begin{array}{c}-0.2915 \\
(0.0000)\end{array}$ & $\begin{array}{c}0.4022 \\
(0.0000)\end{array}$ & $\begin{array}{c}0.1735 \\
(0.0032)\end{array}$ & $\begin{array}{l}-1.7365 \\
(0.0000)\end{array}$ & $\begin{array}{c}0.3333 \\
(0.0270)\end{array}$ \\
\hline 16 & GARCH & $\begin{array}{c}0.9029 \\
(0.0000)\end{array}$ & $\begin{array}{c}0.8944 \\
(0.0000)\end{array}$ & $\begin{array}{c}0.8489 \\
(0.0000)\end{array}$ & $\begin{array}{c}0.5806 \\
(0.0000)\end{array}$ & $\begin{array}{l}-0.4230 \\
(0.0000)\end{array}$ & $\begin{array}{c}0.9026 \\
(0.0000)\end{array}$ \\
\hline 17 & Sign ARCH & $\begin{array}{l}-0.2039 \\
(0.0000)\end{array}$ & $\begin{array}{c}0.0198 \\
(0.5561)\end{array}$ & $\begin{array}{c}-0.1313 \\
(0.0000)\end{array}$ & $\begin{array}{l}-0.0567 \\
(0.3038)\end{array}$ & $\begin{array}{c}0.0975 \\
(0.0625)\end{array}$ & $\begin{array}{c}-0.0658 \\
(0.0981)\end{array}$ \\
\hline 18 & Size ARCH & $\begin{array}{c}0.3252 \\
(0.0000)\end{array}$ & $\begin{array}{c}0.2667 \\
(0.0000)\end{array}$ & $\begin{array}{c}0.2505 \\
(0.0001)\end{array}$ & $\begin{array}{c}0.9344 \\
(0.0000)\end{array}$ & $\begin{array}{c}0.7542 \\
(0.0000)\end{array}$ & $\begin{array}{c}0.2572 \\
(0.0000)\end{array}$ \\
\hline \multirow[t]{2}{*}{20} & Term Spread & $\begin{array}{l}-0.4499 \\
(0.0006) \\
\end{array}$ & $\begin{array}{l}-0.2349 \\
(0.0275) \\
\end{array}$ & $\begin{array}{c}-0.3057 \\
(0.0139) \\
\end{array}$ & $\begin{array}{c}0.0936 \\
(0.6725) \\
\end{array}$ & $\begin{array}{l}-0.3313 \\
(0.4033) \\
\end{array}$ & $\begin{array}{r}-0.0089 \\
(0.9173) \\
\end{array}$ \\
\hline & & \multicolumn{6}{|c|}{ Conditional correlations } \\
\hline 21 & $\begin{array}{l}\text { Chol Factor } 1 \backslash \\
\text { Implied Corr }\end{array}$ & 1 & $\begin{array}{c}0.0317 \\
(0.0163)\end{array}$ & $\begin{array}{c}0.0035 \\
(0.0196)\end{array}$ & 1 & $\begin{array}{c}0.0988 \\
(0.0678)\end{array}$ & $\begin{array}{l}-0.0209 \\
(0.0945)\end{array}$ \\
\hline 22 & $\begin{array}{c}\text { Chol Factor } 2 \backslash \\
\text { Implied Corr }\end{array}$ & $\begin{array}{c}0.0089 \\
(0.4199)\end{array}$ & 1 & $\begin{array}{l}-0.0925 \\
(0.0006)\end{array}$ & $\begin{array}{c}0.0404 \\
(0.0016)\end{array}$ & 1 & $\begin{array}{c}0.0831 \\
(0.0176)\end{array}$ \\
\hline 23 & $\begin{array}{l}\text { Chol Factor } 3 \backslash \\
\text { Implied Corr }\end{array}$ & $\begin{array}{c}0.0148 \\
(0.9326) \\
\end{array}$ & $\begin{array}{l}-1.3715 \\
(0.0166) \\
\end{array}$ & 1 & $\begin{array}{l}-0.0847 \\
(0.6387) \\
\end{array}$ & $\begin{array}{c}0.7938 \\
(0.0483) \\
\end{array}$ & 1 \\
\hline 24 & $\log \mathrm{L}$ & & -519.2868 & & & -1310.8174 & \\
\hline
\end{tabular}

Table 6 - Model 4

\section{Panel A - Estimation}

In his table, we report estimates of the modified EGARCH-M (corresponding p-values in brackets). Models for the UK conditional volatility are estimated using sample 1964:1 - 2004:12. Models for the US conditional volatility are estimated using sample 1950:1 - 2004:12. The triangular decomposition of the variance and covariance matrix is performed in order to identify structural innovations. Output growth is ordered first, inflation is ordered second, and excess return third. The conditional variance model uses the short-term interest rate as exogenous explanatory variable. In rows 1-13 we report estimates of the conditional mean model. Row 14 depicts average monthly risk premium (in percentage terms). In rows 15-19 we report estimates of the conditional variance model. In rows 20-22 we report implied correlations. In rows 20-22 we report estimates of the off-diagonal element $q_{i j}$ of the Cholesky factor matrix (lower triangular matrix) and the implied correlations (upper triangular matrix). Row 23 shows the loglikelihood value that is obtained upon MLE estimation. Bollerslev and Wooldridge (1992) robust quasi-maximum likelihood (QML) estimation of variance and covariance matrix of parameter estimates is calculated.

\begin{tabular}{cccccccc}
\hline \hline & Country & & US & UK & \\
\hline & Variable & IP & CPI & Excess & IP & RPI & Excess \\
& & Growth & Inflation & Return & Growth & Inflation & Return \\
\hline & & & & Conditional mean & & \\
\hline 1 & const & 0.1336 & 0.0717 & & 0.2055 & 0.2620 & \\
& & $(0.0075)$ & $(0.0000)$ & & $(0.0000)$ & $(0.0000)$ & \\
2 & $\Delta \mathrm{y}_{\mathrm{t}-1}$ & 0.2295 & -0.0047 & & -0.1793 & 0.0023 & \\
& & $(0.0000)$ & $(0.5790)$ & & $(0.0005)$ & $(0.8969)$ & \\
3 & $\Delta \mathrm{y}_{\mathrm{t}-2}$ & 0.1247 & -0.0010 & & & &
\end{tabular}




\begin{tabular}{|c|c|c|c|c|c|c|c|}
\hline 4 & $\Delta \mathrm{y}_{\mathrm{t}-3}$ & $\begin{array}{c}0.1314 \\
(0.0005)\end{array}$ & $\begin{array}{l}0.0057 \\
(0.5099)\end{array}$ & & & & \\
\hline 5 & $\pi_{\mathrm{t}-1}$ & $\begin{array}{c}0.0521 \\
(0.6747)\end{array}$ & $\begin{array}{c}0.4013 \\
(0.0000)\end{array}$ & & $\begin{array}{l}-0.1192 \\
(0.0619)\end{array}$ & $\begin{array}{c}0.4377 \\
(0.0000)\end{array}$ & \\
\hline 6 & $\pi_{t-2}$ & $\begin{array}{l}-0.2425 \\
(0.0391)\end{array}$ & $\begin{array}{c}0.1754 \\
(0.0005)\end{array}$ & & & & \\
\hline 7 & $\pi_{\mathrm{t}-3}$ & $\begin{array}{c}0.0049 \\
(0.9694)\end{array}$ & $\begin{array}{c}0.1724 \\
(0.0001)\end{array}$ & & & & \\
\hline 8 & $\mathrm{r}_{\mathrm{t}-1}^{\mathrm{e}}$ & $\begin{array}{c}0.0072 \\
(0.2134)\end{array}$ & $\begin{array}{c}0.0009 \\
(0.7375)\end{array}$ & & $\begin{array}{c}0.0045 \\
(0.6468)\end{array}$ & $\begin{array}{c}0.0040 \\
(0.2780)\end{array}$ & \\
\hline 9 & $\mathrm{r}_{\mathrm{t}-2}^{\mathrm{e}}$ & $\begin{array}{c}0.0234 \\
(0.0030)\end{array}$ & $\begin{array}{l}0.0010 \\
(0.7042)\end{array}$ & & & & \\
\hline 10 & $r_{t-3}^{e}$ & $\begin{array}{c}0.0243 \\
(0.0028)\end{array}$ & $\begin{array}{l}-0.0026 \\
(0.2841)\end{array}$ & & & & \\
\hline 11 & $\operatorname{Var}_{\mathrm{t}-1}\left(\mathrm{r}_{\mathrm{t}}\right)$ & & & $\begin{array}{l}-0.0218 \\
(0.2651)\end{array}$ & & & $\begin{array}{l}0.0100 \\
(0.6953)\end{array}$ \\
\hline 12 & $\operatorname{Cov}_{\mathrm{t}-1}\left(\mathrm{r}_{\mathrm{t}}, \Delta \mathrm{y}_{\mathrm{t}}\right)$ & & & $\begin{array}{l}21.0094 \\
(0.8357)\end{array}$ & & & $\begin{array}{l}-2.2264 \\
(0.8669)\end{array}$ \\
\hline 13 & $\operatorname{Cov}_{\mathrm{t}-1}\left(\mathrm{r}_{\mathrm{t}}, \pi_{\mathrm{t}}\right)$ & & & $\begin{array}{l}-6.4730 \\
(0.1529) \\
\end{array}$ & & & $\begin{array}{c}0.0491 \\
(0.9777) \\
\end{array}$ \\
\hline 14 & $\begin{array}{l}\text { Risk Premium } \\
\text { (Monthly \%) }\end{array}$ & & & 0.8361 & & & 0.1995 \\
\hline & & \multicolumn{6}{|c|}{ Conditional variance } \\
\hline 15 & Const & $\begin{array}{l}-0.0132 \\
(0.4953)\end{array}$ & $\begin{array}{l}-0.2843 \\
(0.0000)\end{array}$ & $\begin{array}{c}0.5782 \\
(0.0002)\end{array}$ & $\begin{array}{l}-0.6863 \\
(0.0060)\end{array}$ & $\begin{array}{l}-3.8427 \\
(0.0000)\end{array}$ & $\begin{array}{c}0.4049 \\
(0.1448)\end{array}$ \\
\hline 16 & GARCH & $\begin{array}{c}0.9276 \\
(0.0000)\end{array}$ & $\begin{array}{c}0.9144 \\
(0.0000)\end{array}$ & $\begin{array}{c}0.7523 \\
(0.0000)\end{array}$ & $\begin{array}{c}0.3219 \\
(0.0038)\end{array}$ & $\begin{array}{l}-0.5408 \\
(0.0000)\end{array}$ & $\begin{array}{c}0.8307 \\
(0.0000)\end{array}$ \\
\hline 17 & Sign ARCH & $\begin{array}{l}-0.2105 \\
(0.0000)\end{array}$ & $\begin{array}{l}0.0015 \\
(0.9653)\end{array}$ & $\begin{array}{l}-0.1987 \\
(0.0000)\end{array}$ & $\begin{array}{c}0.0061 \\
(0.9425)\end{array}$ & $\begin{array}{l}-0.0049 \\
(0.9465)\end{array}$ & $\begin{array}{l}-0.0939 \\
(0.0794)\end{array}$ \\
\hline 18 & Size ARCH & $\begin{array}{c}0.2772 \\
(0.0000)\end{array}$ & $\begin{array}{c}0.2638 \\
(0.0000)\end{array}$ & $\begin{array}{c}0.2297 \\
(0.0001)\end{array}$ & $\begin{array}{c}0.9473 \\
(0.0000)\end{array}$ & $\begin{array}{c}0.5700 \\
(0.0000)\end{array}$ & $\begin{array}{c}0.2639 \\
(0.0156)\end{array}$ \\
\hline 20 & Short Rate & $\begin{array}{l}-0.0385 \\
(0.3443) \\
\end{array}$ & $\begin{array}{c}0.0619 \\
(0.1129) \\
\end{array}$ & $\begin{array}{c}0.5662 \\
(0.0071) \\
\end{array}$ & $\begin{array}{c}1.3191 \\
(0.0002) \\
\end{array}$ & $\begin{array}{c}2.6954 \\
(0.0000) \\
\end{array}$ & $\begin{array}{c}0.2339 \\
(0.2141) \\
\end{array}$ \\
\hline & & \multicolumn{6}{|c|}{ Conditional correlations } \\
\hline 21 & \begin{tabular}{l} 
Chol Factor 1\} $\\
{\text { Implied Corr }}$ & 1 & $\begin{array}{l}0.0213 \\
(0.0179)\end{array}$ & $\begin{array}{c}0.0096 \\
(0.0256)\end{array}$ & 1 & $\begin{array}{c}0.0921 \\
(0.0314)\end{array}$ & $\begin{array}{l}-0.0093 \\
(0.0736)\end{array}$ \\
\hline 22 & $\begin{array}{l}\text { Chol Factor } 2 \backslash \\
\text { Implied Corr }\end{array}$ & $\begin{array}{c}0.0059 \\
(0.5738)\end{array}$ & 1 & $\begin{array}{l}-0.0569 \\
(0.0192)\end{array}$ & $\begin{array}{c}0.0389 \\
(0.0413)\end{array}$ & 1 & $\begin{array}{c}0.0800 \\
(0.0012)\end{array}$ \\
\hline 23 & $\begin{array}{c}\text { Chol Factor } 3 \backslash \\
\text { Implied Corr } \\
\end{array}$ & $\begin{array}{c}0.0397 \\
(0.7949) \\
\end{array}$ & $\begin{array}{l}-0.8263 \\
(0.1065) \\
\end{array}$ & 1 & $\begin{array}{l}-0.0389 \\
(0.8534) \\
\end{array}$ & $\begin{array}{c}0.7780 \\
(0.1286) \\
\end{array}$ & 1 \\
\hline 24 & $\log \mathrm{L}$ & & -526.1801 & & & -1279.6739 & \\
\hline
\end{tabular}
\end{tabular}




\section{Figure 1 - Equity Risk Premia (Model 1)}

This figure depicts the time-varying risk premia for the US (Panel A), UK (Panel B), and UK with a dummy in the conditional mean equation of output growth rate (Panel C), in monthly percentage. The underlying model is the modified EGARCH-M. Models for the UK conditional volatility are estimated using sample 1964:1 - 2004:12. Models for the US conditional volatility are estimated using sample 1950:1 - 2004:12. The triangular decomposition of the variance and covariance matrix is performed in order to identify structural innovations. Output growth is ordered first, inflation is ordered second, and excess return third. The Schwarz Bayesian Information Criterion (BIC) is used to determine the optimal lag length for the restricted vector autoregressions (VARs) in the conditional mean equation (see Panel A). VAR(1) and VAR(3) are selected and fitted for the UK and the US, respectively. The conditional variance model uses the long-term government yields as exogenous explanatory variables. We also provide the decomposition of the risk premia (right graph) due to the macroeconomic factors: output growth (dotted red line) and inflation (dashed green line).

\section{Panel A - US Equity Risk Premium}
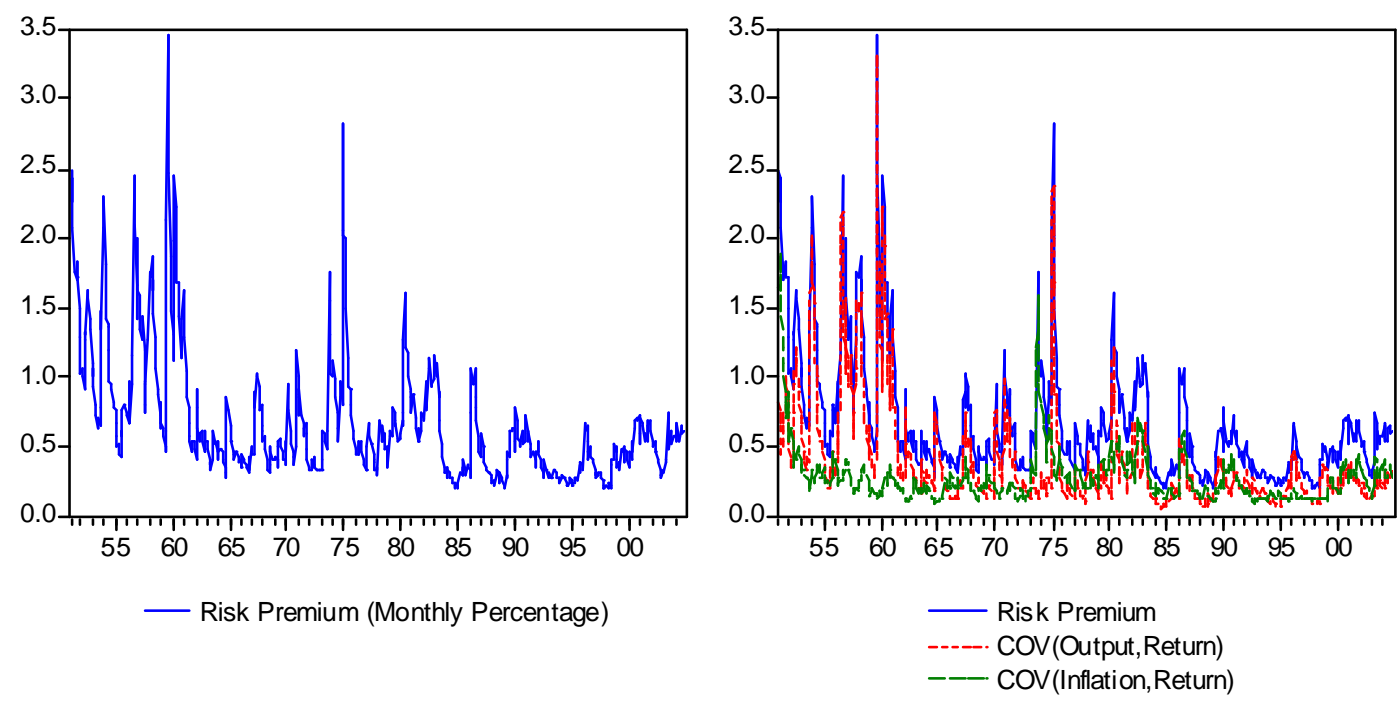

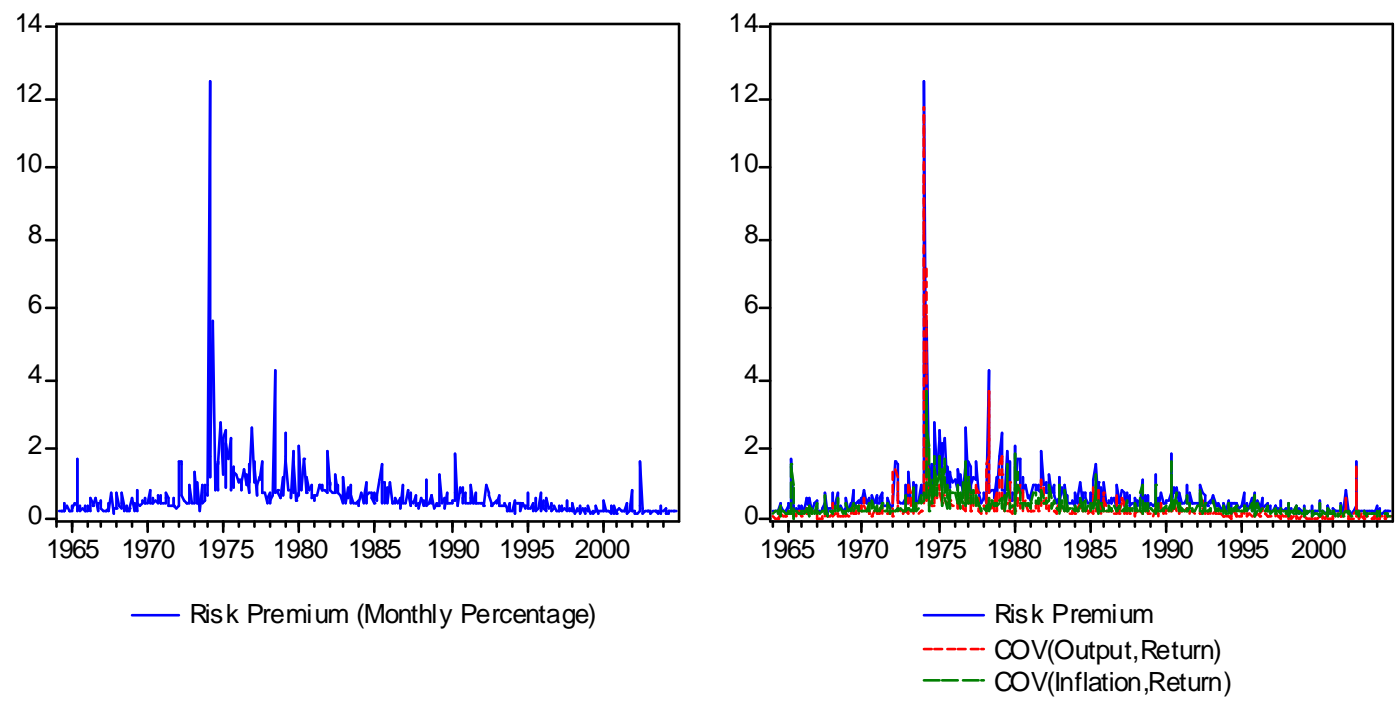

\section{Panel C - UK Risk Premium (Dummy)}
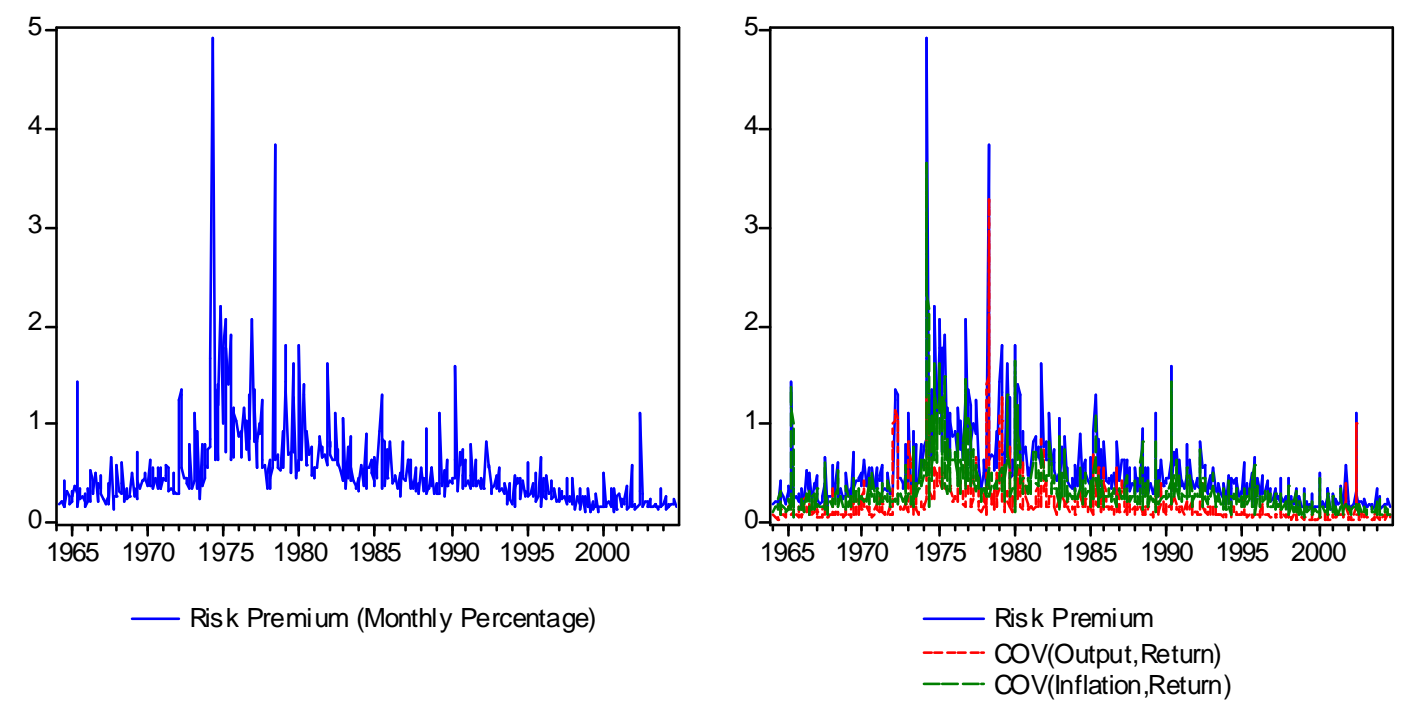

Figure 2 - Conditional Variances (Model 1)

This figure depicts conditional variances of industrial production growth rate (first row), inflation (second row) and stock return (third row) implied by the modified EGARCH-M model for the US (left column) and the UK (right column). Models for the UK conditional volatility are estimated using sample 1964:1 - 2004:12. Models for the US conditional volatility are estimated using sample 1950:1 - 2004:12. The triangular decomposition is performed in order to identify structural innovations. Output growth is ordered first, inflation is ordered second, and excess return 
third. The Schwarz Bayesian Information Criterion (BIC) is used to determine the optimal lag length for the restricted vector autoregressions (VARs) in the conditional mean equation (see Panel A). VAR(1) and VAR(3) are selected and fitted for the UK and the US, respectively. The conditional variance model uses the long-term government yields as exogenous explanatory variables. Time scale is plotted on the horizontal axis, whereas conditional variances (in monthly percentage) are plotted on the vertical axis.

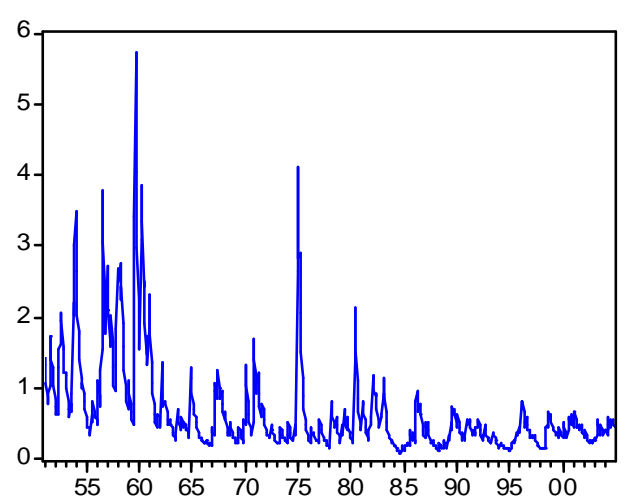

- Conditional Variance of US Qutput Growth

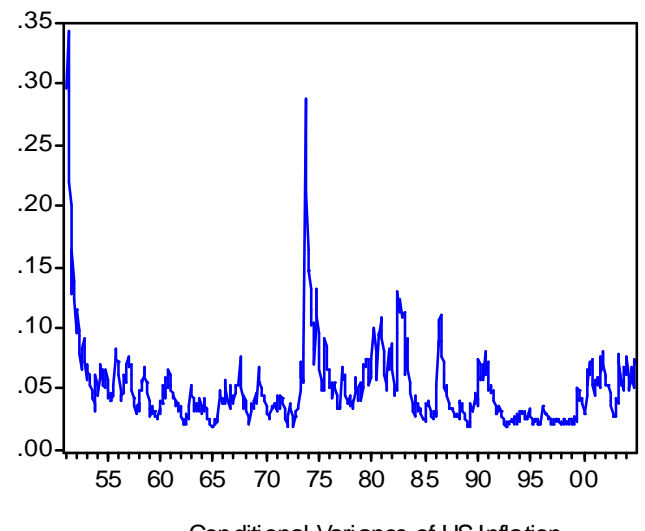

- Conditional Variance of US Inflation

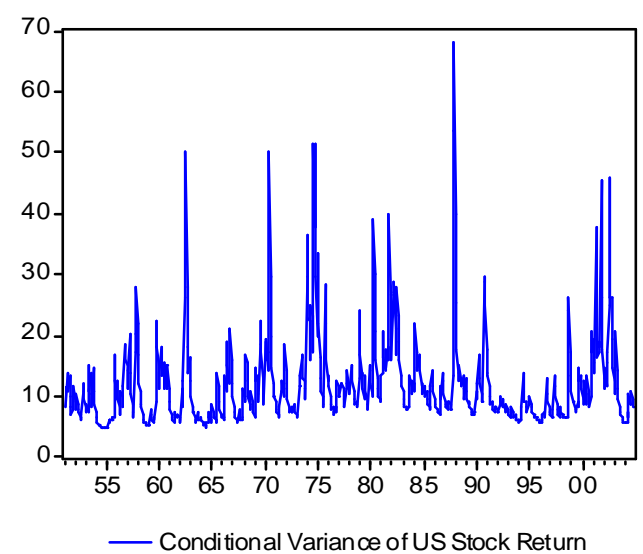

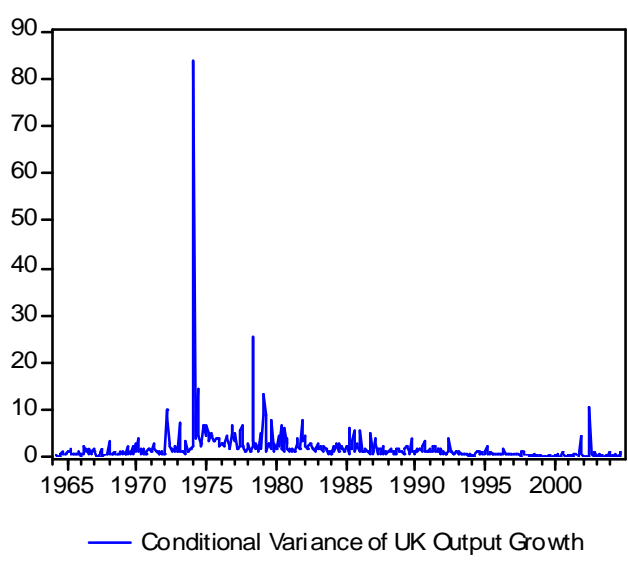
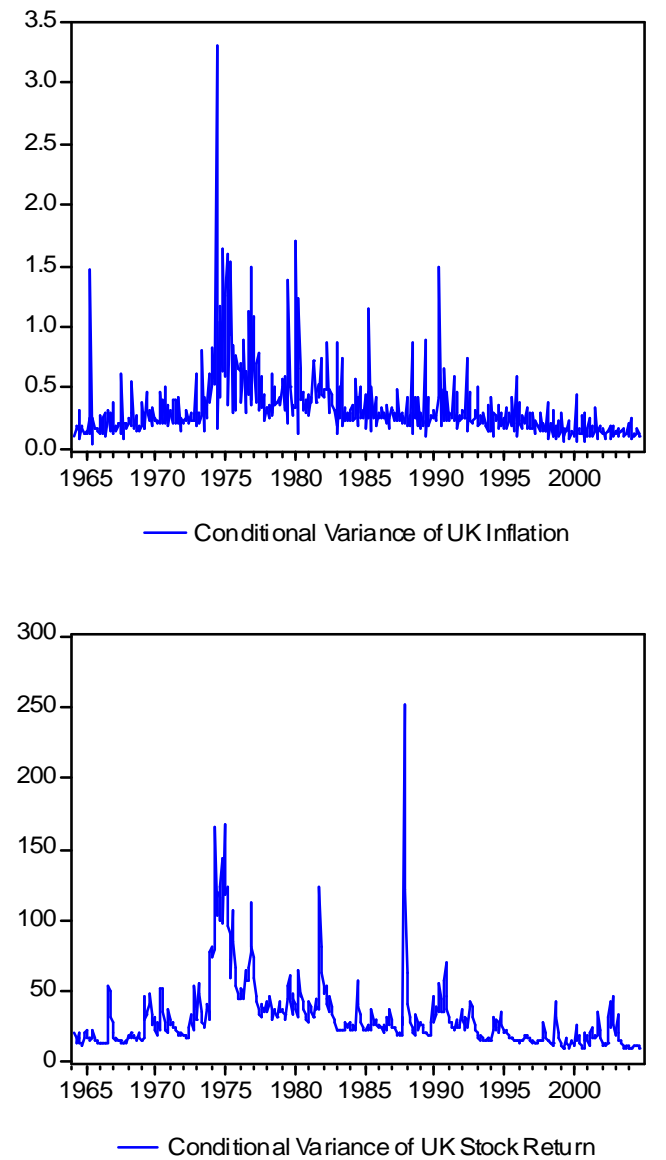

Figure 3 - Time Varying Correlations (Model 1) 
This figure depicts time varying correlations implied by the triangular-decomposition based modified EGARCH-M models. Models for the UK conditional volatility are estimated using sample 1964:1 - 2004:12. Models for the US conditional volatility are estimated using sample 1950:1 - 2004:12. The triangular decomposition is performed in order to identify structural innovations. Output growth is ordered first, inflation is ordered second, and excess return third. The Schwarz Bayesian Information Criterion (BIC) is used to determine the optimal lag length for the restricted vector autoregressions (VARs) in the conditional mean equation (see Panel A). VAR(1) and VAR(3) are selected and fitted for the UK and the US, respectively. The conditional variance model uses the long-term government yields as exogenous explanatory variables. The solid blue line represents the time-varying correlation between residuals from the output equation and the inflation equation, the dotted red line represents the time-varying correlation between residuals from the output equation and the equation of excess return, and the dashed green line depicts the timevarying correlation between residuals from the inflation equation and the equation of excess return.

US Time-Varying Correlations

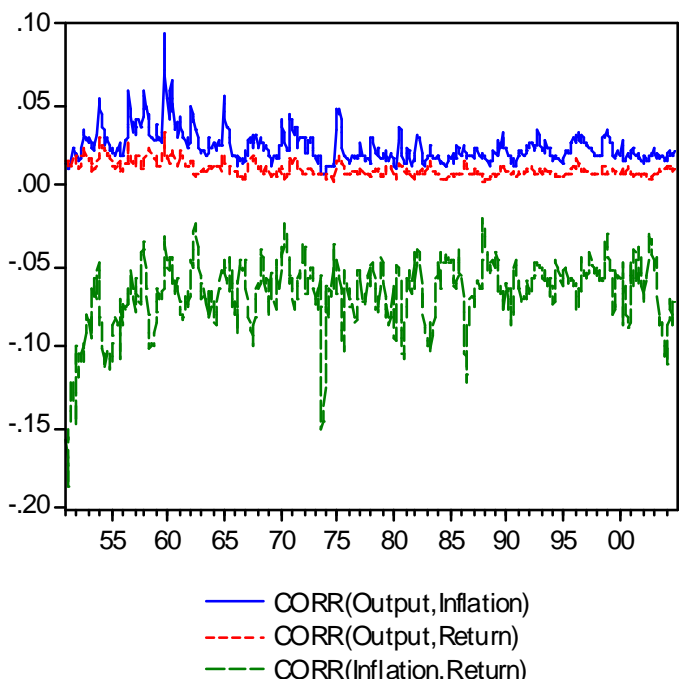

UK Time Varying Correlations

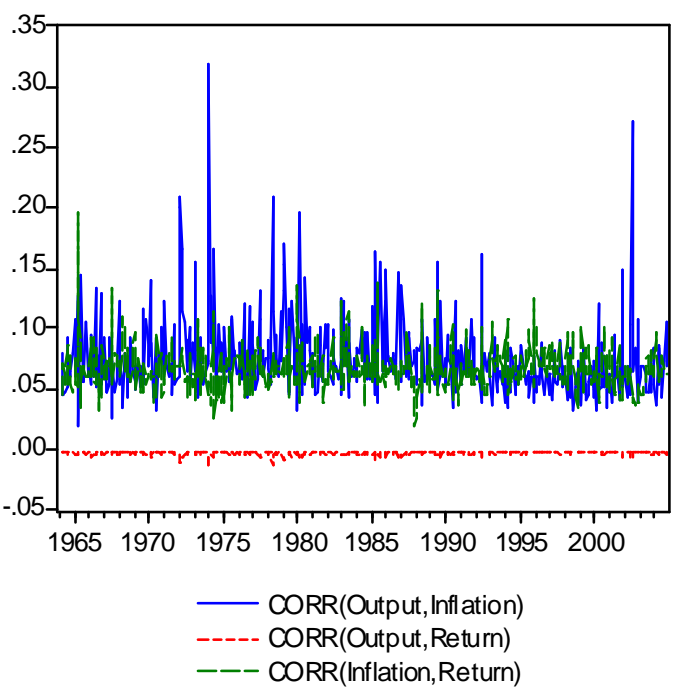

